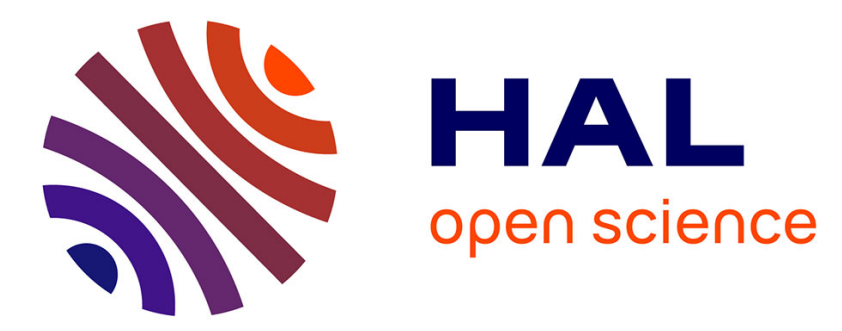

\title{
L'évolution de la topographie de l'Arles antique: un état de la question
}

Marc Heijmans, Claude Sintès

\section{To cite this version:}

Marc Heijmans, Claude Sintès. L'évolution de la topographie de l'Arles antique: un état de la question. Gallia - Fouilles et monuments archéologiques en France métropolitaine, 1994, 51, pp.135170. 10.3406/galia.1994.2975 . hal-01912134

\section{HAL Id: hal-01912134 https://hal.science/hal-01912134}

Submitted on 29 Jan 2020

HAL is a multi-disciplinary open access archive for the deposit and dissemination of scientific research documents, whether they are published or not. The documents may come from teaching and research institutions in France or abroad, or from public or private research centers.
L'archive ouverte pluridisciplinaire HAL, est destinée au dépôt et à la diffusion de documents scientifiques de niveau recherche, publiés ou non, émanant des établissements d'enseignement et de recherche français ou étrangers, des laboratoires publics ou privés.

\section{(ㅇ)(1) $\$$}

Distributed under a Creative Commons Attribution - NonCommercial - NoDerivatives| 4.0 


\title{
L'évolution de la topographie de l'Arles antique. Un état de la question
}

\author{
par Marc HEIJMANS* et Claude SINTÈs*
}

Cet article présente un répertoire des découvertes archéologiques (structures à l'exclusion du mobilier), intervenues ¡'Arles depuis la parution. en 1936, de la Forma Orbis Romani (F.O.R.) consacrée aux Bouches-du-Rhône. Il est $0 . g$ anisé en cinq parties : protohistoire. Haut-Empire. IV $\mathrm{V}^{\mathrm{e}}$ siècle. $\mathrm{V}^{\mathrm{e}}-\mathrm{VI}^{\mathrm{e}}$ siècles, VII ${ }^{\mathrm{e}}-\mathrm{IX}^{\mathrm{e}}$ siècles. Chacune d'entre elles - mprend une introduction établissant brièvement un bilan des connaissances (avec indication des sources), suivi d'un tiventaire topographique où les découvertes, mentionnées et non décrites, sont regroupées par thèmes : enceinte, voirie, ponts, édifices publics, habitat, commerce et artisanat, domaine funéraire. Pour chaque structure, localisée par un ivinbole numéroté sur un plan de la ville actuelle (un plan par période), sont fournies les références bibliographiques, y (ompris les renvois à la $F . O . R$.

This paper gives a list of the archacological structures found. in Arles, since the publication in 1936 of the Forma Orbis Romani. It is separated in five periods, from Preroman times to the IXth century AD. Each part contains an historical introduction, a topographic description organized into different subjects (walls, streets, bridges, public buildings, houses, trades, cemeteries...), and a plan of modern Arles, where the structures are registered. A bibliography of the most recent publications ends the study.

Mots clés : topographie. inventaire. enceinte. voirie. édifices publics, ponts, habitat. domaine commercial, domaine funéraire. Arles. Bouches-du-Rhône. 
En 1936. F. Benoit publiait le volume de la Forma Orbis Romani, consacré au département des Bouches-duRhône, donnant ainsi la première carte archéologique de la ville d'Arles'. Ce travail admirable, encore largement consulté aujourd'hui, prenait en compte l'ensemble des découvertes de l'Antiquité, sans distinction, mais souffrait malheureusement d'une cartographie peu lisible et d'un système de renvois complexe et malaisé.

Le travail présenté ici n'a certes pas la prétention d'être une nouvelle Forma mais plus modestement de répertorier les découvertes intervenues depuis 1936 et qui intéressent la topographie de la ville: toute information mobilière non significative a ainsi été écartée.

Le texte est né de la réalisation d'un DEPAU (Document d’Évaluation du Patrimoine Archéologique Urbain) avec le Centre national d'Archéologie Urbaine de Tours, publié en 1990 ${ }^{2}$. Depuis cette date, notre article s'est enrichi de deux ans de fouilles et découvertes (plusieurs d'une réelle importance pour la ville), de notes, d'un texte plus sûr quant à certaines hypothèses et d'une cartographie complétée ${ }^{3}$.

L'ensemble des notices a été élaboré grâce à la savante participation de Jacques Brémond et Jean Piton et a bénéficié largement, pour la protohistoire, des recherches de Patrice Arcelin. Les cartes ont été, sur le modèle de celles du DEPAU, refondues et augmentées par Jacques Brémond el Ali Aliaoui.

Qu ils soient tous remerciés, de même et surtout que monsieur le professeur Christian Goudineau qui, en nous invitant à le publier dans la revue Gallia, donne à ce travail une chance d’être mieux connu et diffusé.

\section{ARLES PROTOHISTORIQUE}

\section{ÉVOLUTION TOPOGRAPHIQUE (fig. 1)}

L'Arles préromaine était pressentie par les historiens qui, s'appuyant sur les rares textes des auteurs anciens, pensaient qu'une agglomération avait été implantée sur le rocher de l'Hauture dès le Ve s. avant notre èret. Cet emporion créé par les Phocéens ou

I F. BI:Nort, Forma Orbis Romami, Carte archéologique de la Gaule romaine. V. Départeme'nt des Bouches-dut-Rhône. Paris, 1936.

$2 \mathrm{Cl}$. SinTt:s et alii. Documents d'Fraluation du Patrimoine Archéologicue Urhain-Arles, Paris, 1990.

3 Les Documents d'Evaluation comprenaient des notices sur l'Antiquité. le Moyen Age et la période moderne jusqu'au $\mathrm{XIX}^{\mathrm{C}}$ s.. de même que des considérations techniques sur la protection du sous-sol. Bien entendu, ne figurent ici que les feuillets consacrés à l'Arles antique. depuis la protohistoire jusqu'au Haut Moyen Age.

4 C'est L.A. Constans (1921. p. 49) qui. le premier. signala par les Massaliotes serait le Théliné dont le nom nous est parvenu grâce à l'écrivain romain Festus Avienus".

L’absence de témoignage archéologique (jusqu’aux années 1950, seules quelques découvertes avaient été signalées) laissait dans l'ombre la plupart des aspects topographiques et chronologiques. Seules des remarques générales avaient pu être faites sur l'Arles d'avant la colonisation romaine, concluant à un habitat indigène fortement hellénisé, à un lieu d’échange commercial intense sinon privilégié avec Marseille, à une ville puissante à l'économie forte et à l'industrie bien rodée : César, aux prises avec Pompée, trouvera à Arles des chantiers suffisamment équipés et des ouvriers assez adroits pour construire douze bateaux de guerre en un

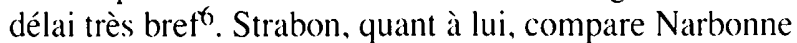
à Arelate, «ville et centre commercial importants» ${ }^{7}$.

Un énorme bond en avant va être fait après la seconde guerre mondiale: l'utilisation de méthodes scientifiques performantes et la multiplication des découvertes vont en effet permettre de mieux connaître les métamorphoses de la ville depuis ses origines. Mais ce n'est qu'à partir de 1975 que l'on a été à même de mieux comprendre, grâce au gisement du Jardin d'Hiver. ce que fut la période protohistorique arlésienne ${ }^{8}$.

A la suite des recherches qu'il mène depuis 1983. Patrice Arcelin a proposé une première esquisse concernant l'évolution de ce comptoir :

- sur l’îlot rochcux, unc présence humaine, dont la composante indigène est quasi exclusive, est attestée dès le début du VI's. avant notre ère. Dès le deuxième quart de ce siècle, la céramique montre qu'un échange commercial, timide d'abord, puis plus soutenu, existe entre la population locale et les marchands qui remontent la basse vallée du Rhône :

- à partir du début du Ves. avant J.-C., l’habitat de la première Arelate déborde du sommet de la butte pour en occuper le flanc sud. L’aménagement en terrasses, le caractère urbain marqué du site à la suite de restructurations topographiques (îlots et rues distribués en trames régulières) ainsi que l’intensification des

qu'Arles avait été implanté «entre le Vé et le $\mathrm{Il}^{e} \mathrm{~s}$. de notre ire». Pour une bibliographic complète, on consultera: Arcelin. 1987 a cl 1990)

5 Fistus A vil:nes, Ora Maritima, 689-691.

6 Cisar, Bollum Civile, I, 36, 4.

7 SIRABON, (jeographica, IV. I. 6.

8 La découverte de ce site majeur a été amené par la création d'un parc à voitures en 1975, suivie d'une prospection archéologique en 1976 réaliséc par J. Brémond et J. Piton (Musees d'Arles) et (h. Lagrand (CNRS). A partir de 1983. P. Arcelin (CNRS) a mis en place un programme de recherches qui se poursuivit jusqu'en 1989. Voir: Arcelin, 1990, pour la mise au point la plus récente, avant publication. 
échanges économiques entre Arles et Marseille, et plus généralement Arles et le monde méditerranéen, semblent indiquer que cette ville était devenue un emporion. Ce comptoir, fondé en même temps que d'autres dans le sud de la Gaule, témoigne du mouvement de conquête économique :

- un siècle plus tard, pourtant, une refonte de l'urbanisme est sensible, principalement sur le site du Jardin d'Hiver où des surfaces plus étendues que partout ailleurs ont pu être observées et explorées : le mélange des traits méditerranéens pour l'organisation urbaine et des caractères indigènes pour l'organisation intérieure de l'habitat a été mis en lumière par les travaux récents. De la même manière, la céramique souligne la vitalité de la production locale. Ces observations suggèrent bien évidemment une domination ethnique indigène renouvelée, qui prendra désormais le dessus jusqu au II's. avant notre ère.

Des sondages de reconnaissance, dans la partie nord des cryptoportiques, ont montré la richesse de ce site, comme le laissait déjà supposer les fouilles inédites de Fernand Benoit en 1942 et 1943.

Enfin, des travaux récents dans l'église des Prêcheurs ainsi quau nord, dans les maisons aroisinantes, ont révélé la présence d'un ensemble de murs en grand appareil à bossage, formant un carré de $25 \mathrm{~m}$ de côté, et conservé jusqu'à une hauteur de $12 \mathrm{~m}$. Leépaisseur du mur dans l'égiise des Prêcheurs est de $1.20 \mathrm{~m}$, les autres atteignent plus de $6 \mathrm{~m}$ en fondation et $2.20 \mathrm{~m}$ en élévation. Le contexte archéologique laisse croire qu'il s'agit d'une construction préaugustéenne, mais la technique d'assemblage des blocs doit faire descendre la datation jusqu à la période protoaugustéenne". L'interprétation de cet ensemble monumental reste en suspens, cependant une structure de cette importance a peu de chance d'être autre que militaire.

\section{REPÈRES TOPOGRAPHIQUES}

\section{Enceinte}

- Murs en grand appareil (1) (fig. 2). Ces murs sont conservés in situ dans l'église des Prêcheurs comme dans les maisons voisines au nord. D autres sondages dans l'église, de surfaces réduites, ont donné des vestiges de murs, en pierres sèches, également attribuables à une période préaugustéenne.

FOR, V. 131, p. 142 : Gallia lnformations, 1990, 1-2, p. 152 : Heijmans. Brémond, 1994 : étude en cours.

9 Cf. M. FINCKI:R, Technique de construction romaine : la pince à crochet, un systeme original de mise en axuvre des blocs de grand appareil. RAN 19. 1986. p. 331-3.36.

\section{Édifices publics}

- Angle de mur à bossage (2), mis au jour par F. Benoit en 1942. Une étude récente permet de le dater du début du Ier s. avant J.-C. Ce bâtiment a été construit sur l'angle d'un îlot occupé depuis le Ves. avant notre ère (fig. 3).

Amy, 1973, p. 280, fïg. 4, pl. 6 (T) : élude en cours.

- Murs en pierres sèches (3) liées à l’argile, très épais, observés lors de la construction de la cité administrative.

Renseignement oral : photographie conservée au muséc de l’Arles Antique.

\section{Voirie}

- Des sondages récents dans la partic nord des cryptoportiques ont montré une occupation quasi permanente du $\mathrm{VI}^{\mathrm{e}}$ au $\mathrm{I}^{\mathrm{er}}$ s. avant J.-C. (4). Cette occupation est notamment marquée par une succession de rues, dont l'orientation (constante du Ve au Jer s.), sera respectée par les architectes romains lors de la construction des cryptoportiques.

Heijmans. 1991, p. 171-174: étude en cours.

\section{Habitat}

- L'habitat le mieux documenté pour la période protohistorique est bien évidemment celui fouillé actuellement sous le Jardin d'Hiver (5) (fig. 4).

Gallia, 44, 1986, p. 391-393: Gallia Informations.

1987-1988, 2, p. 229-231: 1990, 1-2, p. 141-14.3: Arcelin. 1987b: 1990.

- Des structures en briques de terre cruc et en picres sèches semblables à celles du Jardin d'Hiver, ont été découvertes dans les fouilles de Sainte-Luce (6). La datation montre une occupation du $\mathrm{II}^{\mathrm{e}}$ ou du $\mathrm{I}^{\mathrm{er}} \mathrm{s}$. avant notre ère, avec cependant des formes plus anciennes ( $\mathrm{V}^{\mathrm{C}}$ et $I^{\mathrm{e}} \mathrm{s}$. avant J.-C., qui se retrouvent dans des remblais profonds.

Gallia, 44, 1986, p. 402: Gallia Informations, 1987 1988,2 , p. 231.

- La fouille à l'emplacement du Musée de l'Arles Antique (I.R.P.A.) a permis la mise au jour d'un habitat isolé (ferme?), datable de la fin du Ves. au début du IVes. avant J.-C. (7) (fig. 5). Cette découverte confirme les observations faites pendant les travaux de l'écluse en 1970 (13).

Sintès, 1990a, p. 11-12: Gallia Informations, 1990, 1-

2. p. 144-145: étude en cours.

- Des sondages profonds sur le site de l’Esplanade ont livré des traces d'une occupation de l'époque protohistorique $\mathbf{( 8 )}$. Il s'agit certainement de la continuation du quartier du Jardin d'Hiver.

Gallia. 35. 1977, p. 517 ; Congès et alii. 1992, p. 122. - Les fouilles plus anciennes avaient livré des sols d’habitat et des remblais avec une fréquence élevée de céramiques préromaines, en d'autres points de la ville: à la nouvelle Poste $(9)$, à la Major (10), dans l'église Saint-Blaise (11), à côté de la place de la République 


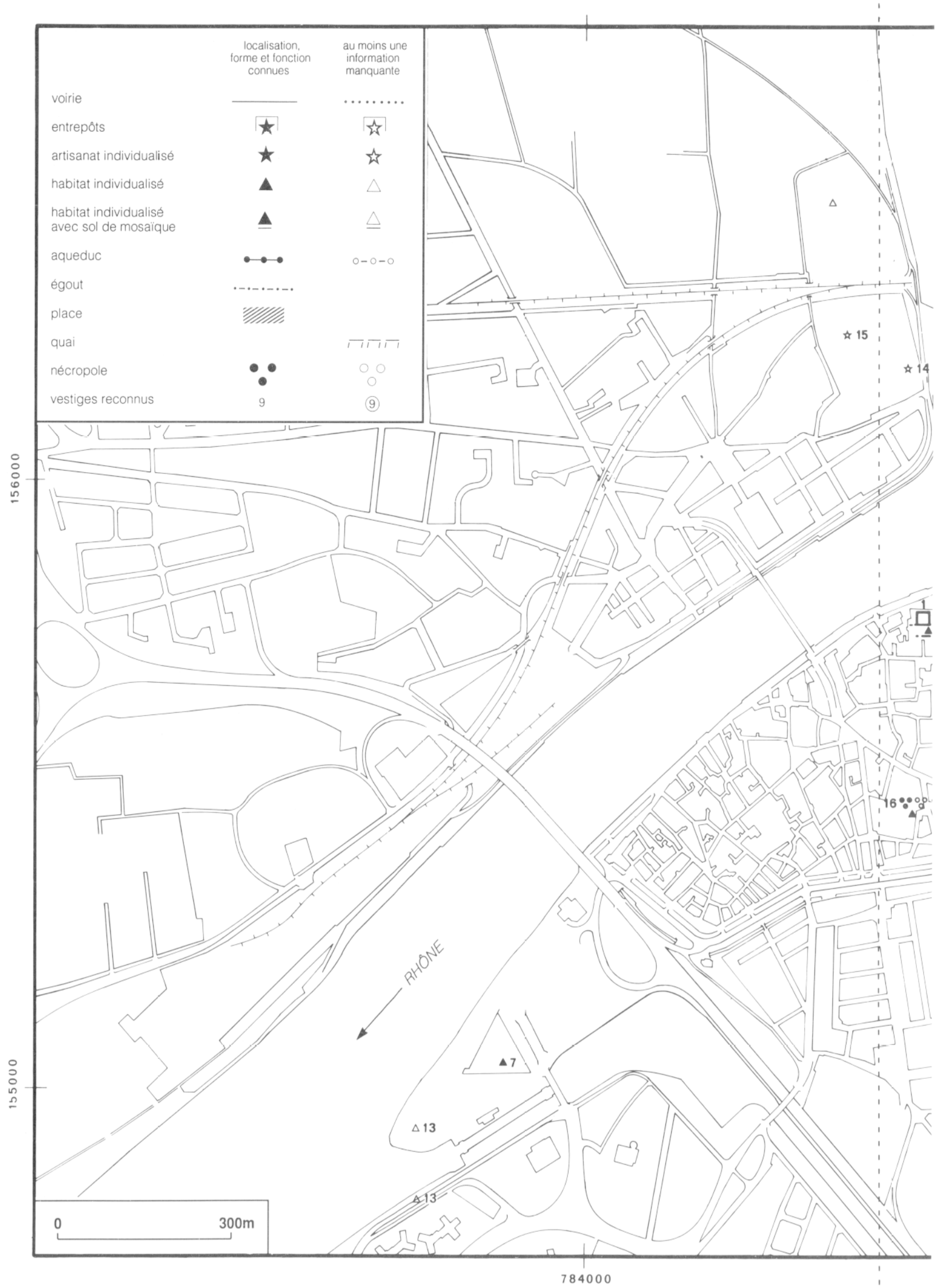




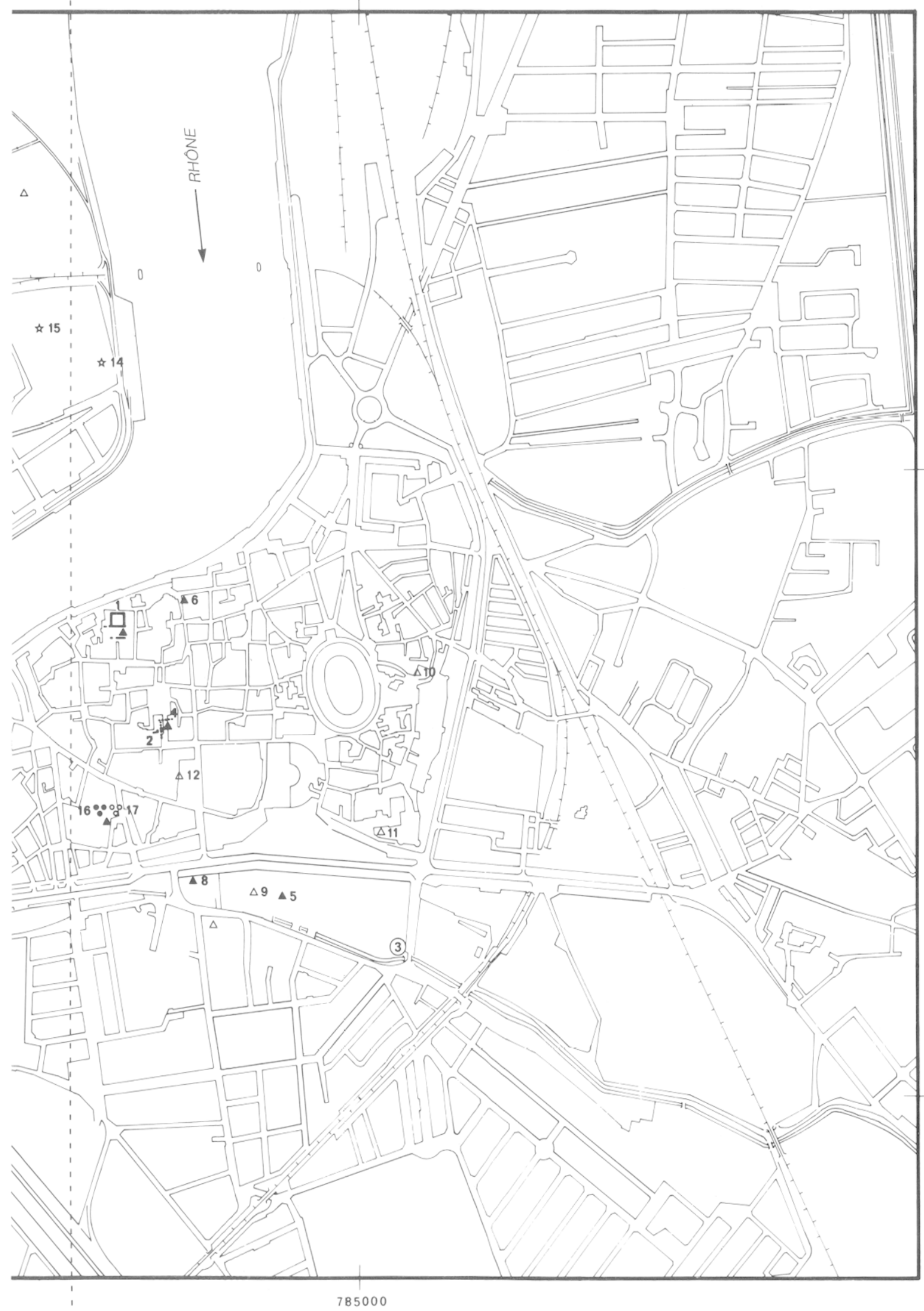

Fig. 1 - Plan 1 : Arles protohistorique. 


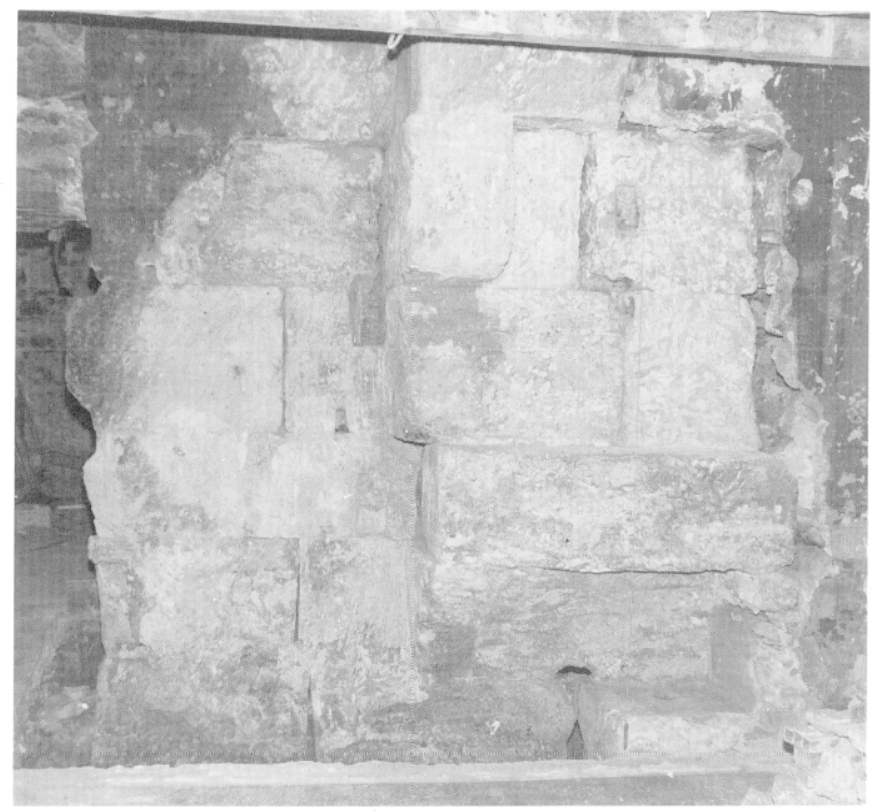

Fig. 2-Arles protohistorique (cf. fig. 1. 1). Mur en grand apparcil. à bossage, dans une maison. le long du Rhône.

\section{Fïg. $3-$ Arles protohistorique (cf. fig. 1, 2). \\ Angle d'un monument pré- romain. dans les cryptoportiques.}

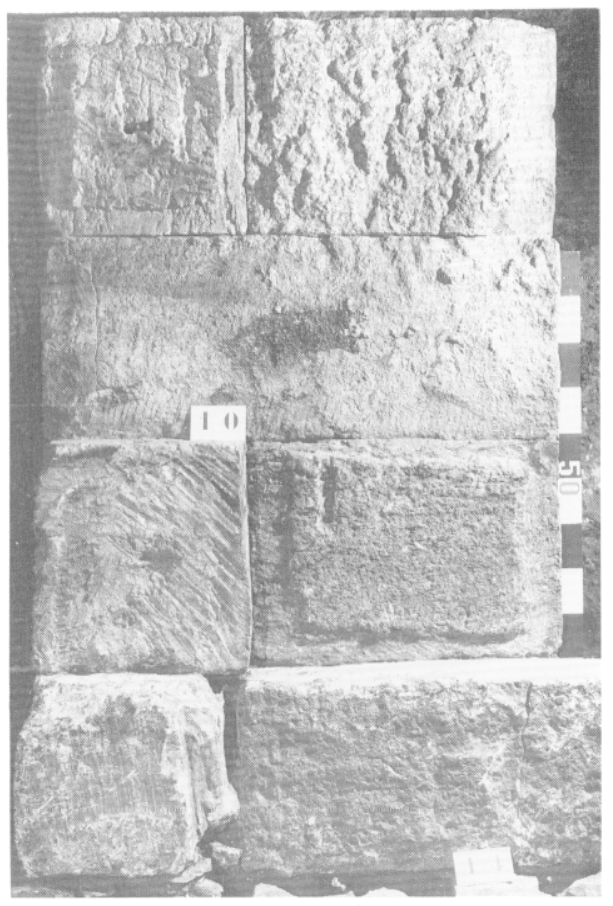

Fig. 4 - Arles protohistorique (cf. fig. 1,5). Jardin d'Hiver (vue des fouilles).

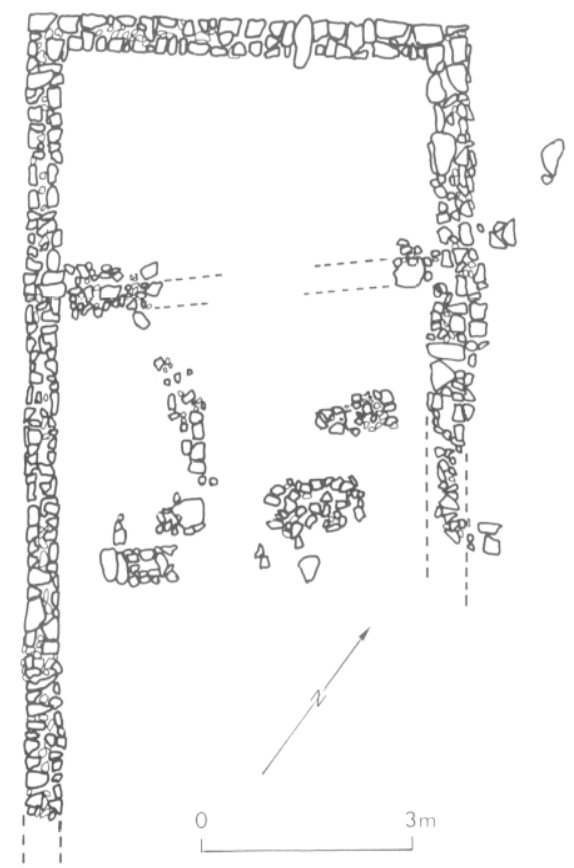

Fig. 5 - Arles protohistorique (cf. fig. 1.7).

Elablissement protohistorique. sur le chantier de I'I.R.P.A.

Plan de l'ensemble.

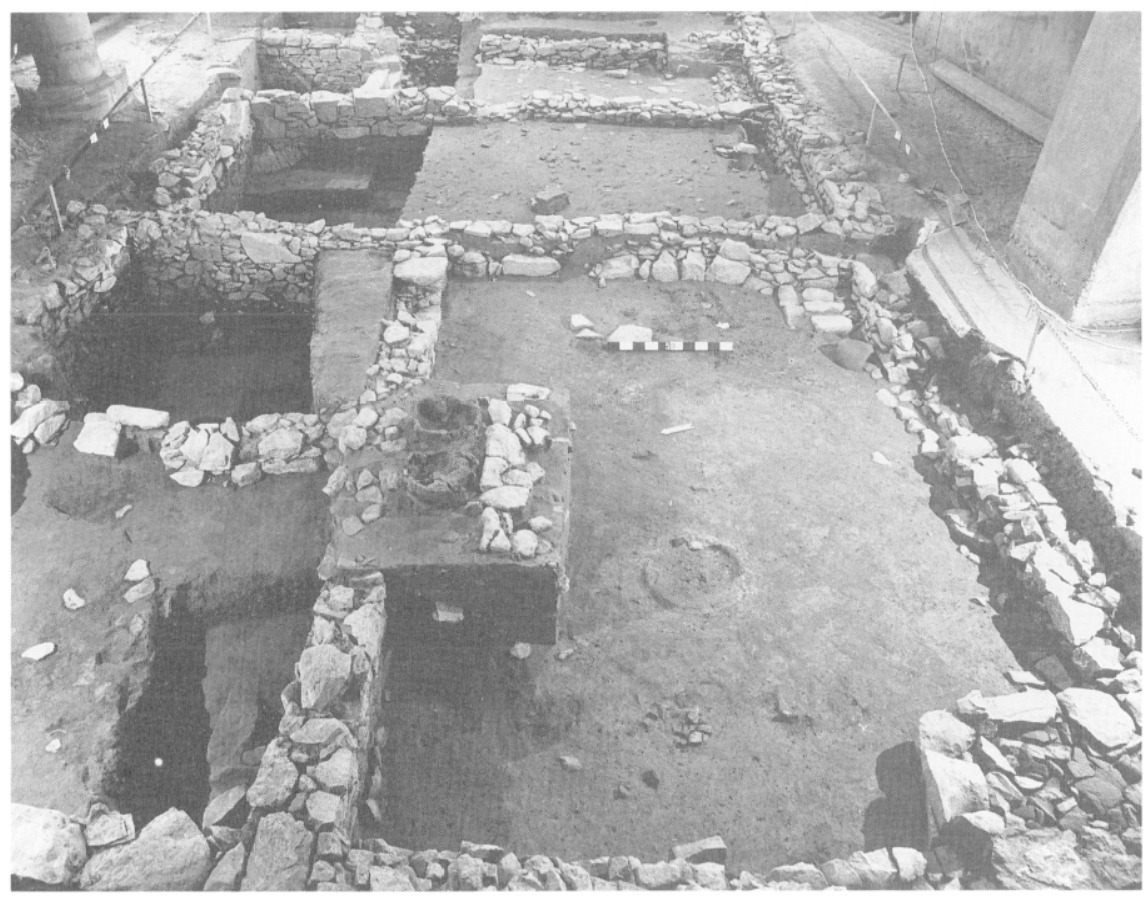

(12) et à l'extérieur de la ville, au bout de la presqu'île du cirque romain (13), où des monnaies massaliotes en argent furent découvertes en assez grand nombre lors des travaux de l'écluse.

Renseignements oraux. Areelin. 1987a et 1990).

\section{Commerce et artisanat}

- Des tessons de céramique d’imitation campanienne. déformés, et des rebuts de cuissons ont été mis au jour en deux points ( 14 et 15), éloignés l'un de l'autre d'une centaine de mètres, dans le cimetière de Trinquetaille. Il pourrait s'agir des déchets d'un atelier de potier.

Renseignements oraux uniquement : matériel conservé au musée de l'Arles Antique. 


\section{Funéraire}

- Nécropole de l’hôpital Van-Gogh (16). Une nécropole avec des urnes cinéraires du Ier $s$. avant J.-C. a été fouillée en 1986. Les umes étaient installées dans un secteur occupé dès la première moitié du VI's. avant J. - C.

Sintès, 1987h. p. 101-103.

- Nécropole du Crédit Lyonnais (17). A côté de la nécropole de l'hôpital Van-Gogh. sur le site du Crédit Lyonnais, une fouille de sauvetage avait permis (en 1967) de récupérer quelques amphores et jarres ayant servi d'urnes à incinération. Il s'agit vraisemblablement de la suite de la nécropole fouillée à Van-Gogh (16).

Sintès. 1987h. p. 103.

\section{ARLES AU HAUT-EMPIRE (du Ier au III s.) $^{\text {er }}$}

\section{ÉVOLUTION TOPOGRAPHIGUE (fig. 6)}

César, dont on a vu qu il avait trouvé un appui décisif auprès des Arlésiens. va très vite comprendre l“intérêt économique du site en tête du delta du Rhône. C'est donc peu après sa victoire en 46 avant J.-C. qu ii] déduira une colonie de droit romain, avec les vétérans de la VIC légion conduits par Claudius Tiberius Nero ${ }^{10}$. colonie à laquelle il rattachera la majeure partie du vaste territoire marseillais. Ce geste, inspiré par la reconnaissance, mais aussi par le souci daffaiblir considérablement Marseille qui, pour son malheur, avait choisi le parti de Pompée, sera à l’origine de la prospérité arlésienne.

Arelate, devenue sous Octave et en hommage au grand stratège Colonia Julia Paterna Arclate Sextanorum, va connaître un premier plan d'urbanisme conçu peut-être dès sa fondation, mais que toutes les traces visibles rattachent à la période augustéennell.

Le parcellaire garde encore très présente dans la partie basse de la ville (fig. 7 : la Cité) la trame urbaine imposée par les Romains. Le quadrillage était rigoureusement aligné nord-sud et est-ouest autour de ses deux axes principaux: le decumanus (approximativement l'actuelle rue de la Calade ou une rue parallèle) et le (ardo (rue de l'Hôtel-de-Ville) dont l'extrémité méridionale a été rctrouvée en 1977 près du kiosque à musique (fouilles de l'Esplanade).

Des îlots d'habitation que l'on peut supposer larges d'une cinquantaine de mètres ${ }^{12}$, sans encore pouvoir l'affirmer, étaient inscrits dans ce réseau avec, par endroits, des espaces plus vastes réservés à la construction des grands monuments publics. Cet arearum electio. ainsi que le nommait Vitruve, est particulièrement évident: le théâtre, le forum (les

10 SLETONE. Iita Tiberii. IV. 2

11 Cf. Gros, 1987, p. 342.

12 Selon l'hypothèse de Benoit. 1964, p. 157. cryptoportiques). l'exèdre du Museon Arlaten. les thermes de la place de la République (vus au moment de l’installation de l'obélisque au XVII's. et qui semblent, d’après les descriptions anciennes, parallèles à l'ancien archevêché) et les thermes du Nord (qui sont plus tardifs) s inscrivent très précisément dans cette vaste composition urbaine.

L'Hauture, située au sommet de la butte rocheuse. ne présente au contraire aucune trame orthonormée visible. Il semble que ce quartier (qui se trouve peut-être à l'emplacement du (castrum césarien) soit resté à l’écart de l'organisation spatiale, bien qu'il ait fait partie intégrante de la ville: le mur d’enceinte augustéen l'englobe largement.

Vers l'ouest, il est aussi bien difficile de comprendre la topographie des premiers siècles : le faubourg de la Roquette dont on a dit un peu rapidement qu il était le quartier indigène, par opposition au quartier romain bien organisé de la Citél3. est très mal connu. Des découvertes anciennes de mosaïques montrent que des constructions existaient certainement entre le cœur de la ville et l'emplacement du futur cirque, mais il est délicat de donner des datations concernant son apparition $^{14}$.

L’arc du Rhône dans le quartier du Méjan, dont l'étude de quelques dessins du XVII' $s$. montre qu’il est d'époque augustéenne, pourrait être caractéristique d’un changement d'orientation du plan de la ville si on le compare à l'arc de Timgad, par exemple. D'autres hypothèses sont pourtant également plausibles : départ d'un pont sur le Rhône, ou arc enjambant une voie nord-sud ${ }^{15}$. En tout cas. les fouilles de l'hôpital VanGogh ont révélé récemment qu'une vaste esplanade existait au sud-ouest du forım et ce dès le milieu du Ior s. au moins.

Cette place dallée de calcaire froid remet en cause le tracé du mur d'enceinte supposé pour l'ouest de la ville, tel que F. Benoit l'avait proposé, et oblige à considérer la Roquette comme une zone plus urbanisée qu il n'y paraissait, avec peut-être une organisation monumentale importante.

De l'autre côté du fleuve, à Trinquetaille, quelques murs, quelques découvertes, montrent une timide implantation intervenant vers le début de notre ère et sans doute localisée près des ponts. Les fouilles sur le site de Brossolette ont ainsi révélé la construction d'un habitat aux alentours des années 5-20 après J.-C. L'orientation du quadrillage (sud-est/nord-ouest) légèrement déviée par rapport à celui du centre-ville, ne va plus beaucoup évoluer depuis cette période jusqu au IIIC s. $^{16}$

13 Cf.. par exemple. Benoit. 1941.p. 98.

$14 \mathrm{Cf}$. comme découvertes anciennes, F.O.R. 147. 154. 167. p. 143.

15 Cf. Daniel. Heijmans. 1992, p. 97.

16 Sintès, 1992, p. 136 



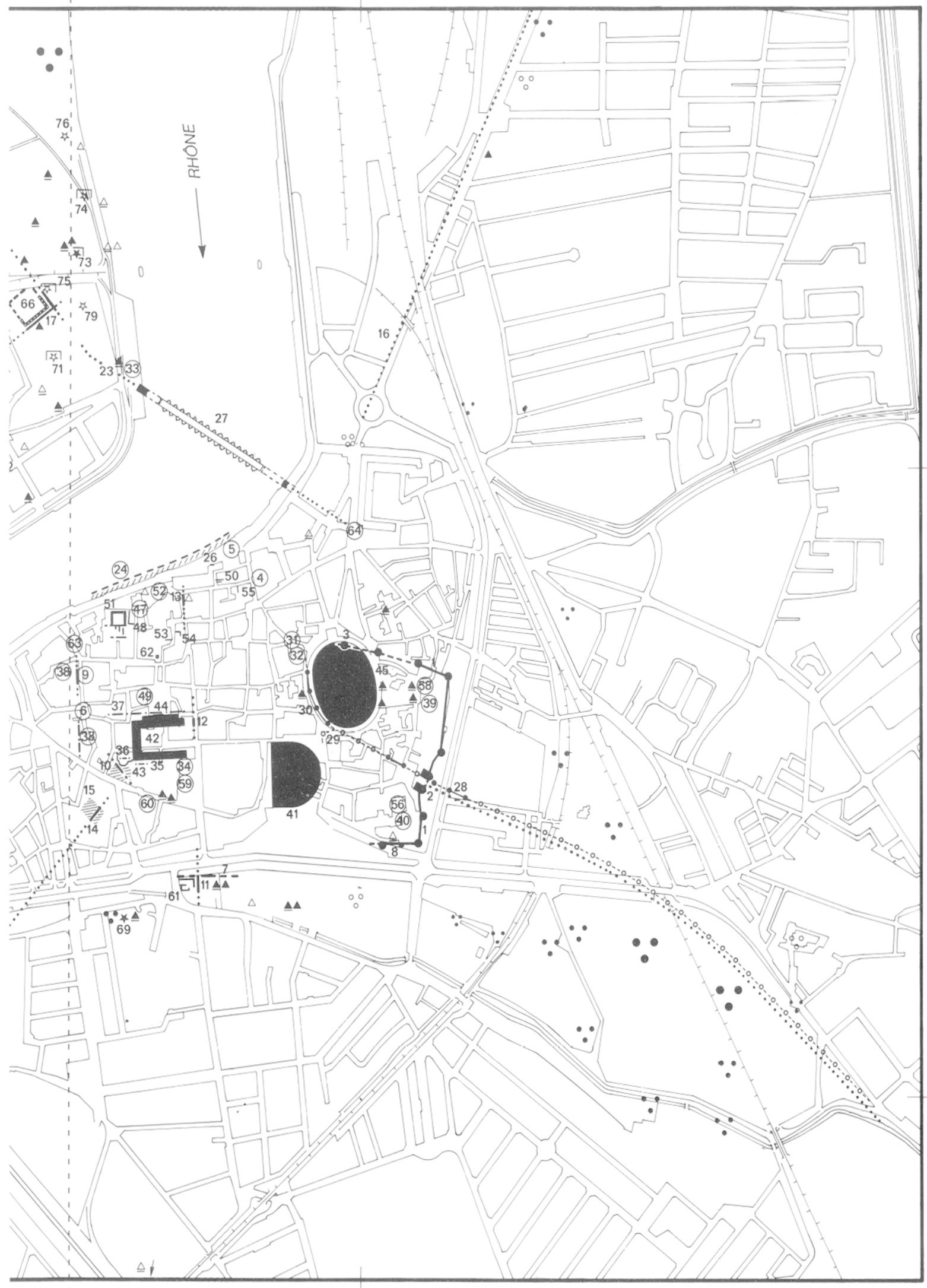

Fig. 6 - Plan 2 : Arles au Haut-Empire. 


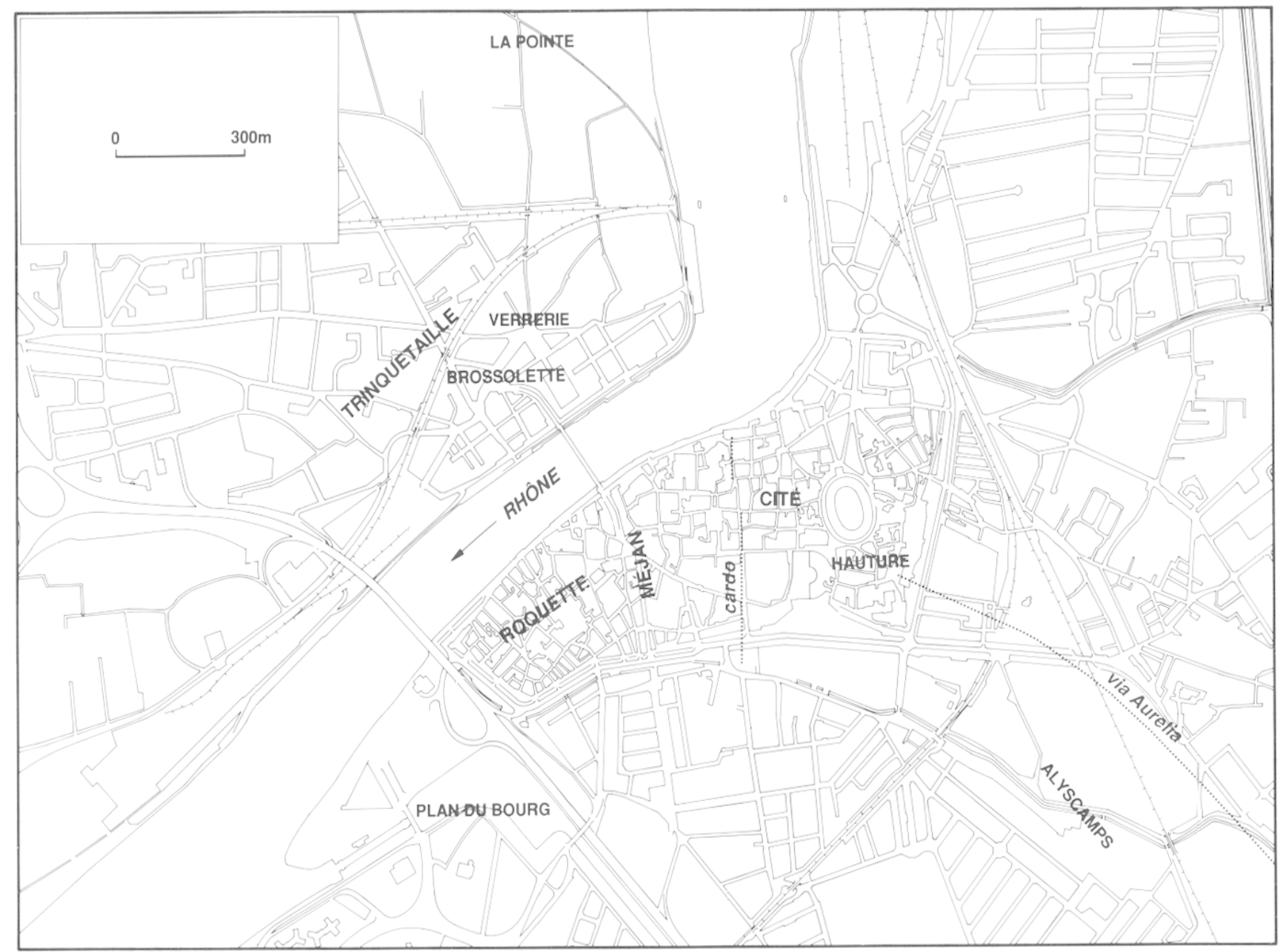

Fïg. 7 - Plan de situation des différents quartiers d`Arles.

Les nécropoles se développent le long des voies d'accès, autour de la voie aurélienne venant d'Italie (à l'emplacement de ce qui deviendra le cimetière des Alyscamps au Moyen Age), le long du bourrelet alluvial à l'ouest de la ville (près du cirque), le long de la voie se dirigeant vers Ernaginum (route d'Avignon), et, à Trinquetaille, au lieu dit la Pointe et le long de la route des Saintes-Maries-de-la-Mer (fouilles de la Gare Maritime, en 1874/1875).

Vers la fin du Iers. après J.-C., au cours de la période flavienne, la ville va littéralement éclater et déborder par delà le corset désormais trop étroit des murailles élevées sous le principat d'Auguste.

Cette phase de prospérité, liée à une intense activité économique et à un enrichissement de la population, est particulièrement marquée à Trinquetaille, où se développe un quartier très riche. Les fouilles montrent que les constructions modestes de l'état précédent sont modifiées, agrandies, avec un luxe et un raffinement décoratif remarquables.

Cet habitat résidentiel se double, vers le nord, d'une zone à vocation industrielle : le long du fleuve, des entrepôts, des quais et des établissements de type artisanal sont construits. La découverte la plus importante reste le monument du cimetière de Trinquetaille où un vaste espace, bordé d un portique et de locaux, fait penser au forum des Corporations à Ostie.

Il est actuellement bien délicat de donner une limite à l'espace urbanisé antique pour la rive droite: une découverte fortuite récente montre qu un habitat, du même type que ceux découverts à la Verrerie et à Brossolette, se développait bien au-delà des entrepôts déjà reconnus. Cet habitat, non encore fouillé, est en tout cas lié au schéma urbain général du faubourg puisque l'orientation des murs reprend très exactement le quadrillage relevé par ailleurs à Trinquetaille. La densité des maisons, la présence de rues publiques interdisent d'y voir une construction indépendante (grande villa rurale, par exemple) ${ }^{17}$.

Sur la rive gauche, les transformations de la fin du fơ s. sont encore plus évidentes. L’arasement des

17 Pour un autre exemple d'urbanisme réglé avec voies, dans le quarticr, voir: Gallia Informations, 1990, 1-2, p. 149150. 
remparts dans la partie nord-est de la ville favorise la naissance d'un nouveau quartier avec son système viaire organisé atutour de l’amphithéâtre. On remarquera que ce dernier n'est plus inscrit dans la trame originelle, mais forme avec elle un angle assez marqué. suggérant le changement de parti urbanistique et peut-être aussi les difficultés que les ingénieurs romains ont dû rencontrer pour intégrer une telle masse architecturale dans la ville.

A l'opposé de l’amphithéâtre, vers l'ouest, le cirque est construit entre le fleuve et la nécropole du Plan-duBourg. Les deux monuments avaient une capacité similaire, qui avoisinait les vingt mille spectateurs.

Dans le centre ville. la Cité proprement dite. le réaménagement monumental semble avoir été là aussi radical. Les fouilles de l'hôpital Van-Gogh en ont apporté la preuve: la place construite au milieu du I's s. est remaniée, agrandie, embellie vers la fin de la période flavienne. Une voie dallée. bordée à l'ouest par un portique, la traverse. Il ne fait pas de doute que les urbanistes ont voulu accentuer le lien existant entre le cour de la ville (l'esplanade s'articule avec le forum tout proche) et l'ensemble cirque-nécrople du Plan-duBourgls.

Le développement et la prospérité d’Artes vont pourtant cesser momentanément au cours de la seconde moitié du $I I^{\circ}$ s. à la suite de désordres graves qui affectent les zones extérieures. A Trinquetaille, le site de la Verrerie, celui de Brossolette, comme ceux fouillés par F. Benoit puis J.-M. Rouquette près du clos SaintJean. présentent des caractéristiques similaires: développement d'un riche quartier suburbain dont la croissance est brutalement arrêtée par des incendies et des destructions intervenant dans les années 250-290.

Ce phénomène a été observé aussi rive gauche, sur les chantiers du Crédit Agricole et de l’Esplanade, où de riches maisons sont détruites dans les années 250-270. avant de devenir des carrières pour les récupérateurs.

Ce n’est qu’à partir de Constantin qu`Arles retrouvera une place de premier ordre imputable à son rôle politique et administratif accru.

\section{REPÈRES TOPOGRAPHIQUES}

Pour le Haut-Empire. F. Benoit ayant dépouillé toute la bibliographie antérieure à 1936. on a donné ici la référence à la Forma Orbis Romani (F.O.R.) sous une forme simplifiée. ce qui permet de trouver facilement toutes les mentions anciennes. Pour les ouvrages publiés après 1936. on a, en général. mentionné les synthèses les plus importantes ou les ouvrages les plus récents.

18 Pour l'orientation de cette voie et le schéma urbain général, voir: Sintès, 1992, p. 138-141.

\section{Enceinte}

Les murs d'enceinte augustéens, construits en petit appareil smillé, sont bien lisibles pour toute la portion orientale comprise entre la tour des Mourgues et la porte Agnel. Le rempart prend ensuite une direction nord-ouest, vers l'amphithéâtre : il a été fouillé par $F$. Benoit dans les substructions nord de ce monument. Plus loin, vers le fleuve, quelques murs ont été signalés autour de l'église Saint-Julien êt près du Rhône. La localisation du rempart est moins connue au sud de la ville et surtout à l’ouest. Le gros mur épais découvert dans les fouilles de l'Esplanade (7) semble être le premier fragment méridional reconnu du rempart. mais il est difficile de lier ce tronçon et celui à l'ouest de la tour des Mourgues. Pour la limite ouest de la ville, nous n`avons aucun élément sûr, mais il semble que la ville soit plus étendue que ne le croyait autrefois $F$. Benoit $^{19}$.

- Murs d'enceinte augustéens (1).

$$
\text { F.O.R., 50, 52, 70, p. } 127 .
$$

- Porte "de la Redoute». dite porte d’Auguste (2). Porte d'accès à l’arrivée de la voie aurélienne.

F.O.R.. 52. p. 127.

- Mur dans l'amphithéâtre (3).

Gallia. VI. 1948. p. 209-210.

- Mur près de Saint-Julien (4) ? Un sondage récent au nord de l'église n'a pas permis de trouver trace de ce mur.

F.O.R.. 89, p. 127.

- Mur près du Rhône (5) : enceinte ?

F.O.R. 1.34, p. 144.

- Tour observée anciennement et démolie vers 1650)(6). Il est difficile de dire s`il s`agit d’un bâtiment antique faisant partie de l'enceinte (porte décumane ouest), comme le pense F. Benoit, ou bien d'une tour médiévale. Elle est connue au Moyen Age comme Tour du Vallat (Tour du «Fossé») et A. Véran pense qu elle aurait fait partie de l’enceinte médiévale séparant la Cité du Méjan.

Véran, in: Le Musée, $\mathrm{n}^{\circ} 4$ (3 série), 1876, p. 32 :

F.O.R. 139, p. 128.

- Mur de l’Esplanade (7) (fig. 8). L’interprétation de ce mur comme partie de l'enceinte semble assurć, malgré les réserves émises au moment de la découverte.

Gallia, 44, 1986, p. 389 : Congès, 1987, p. 39 :

Congès et alii. 1992. p. 122.

- Mur, situé montée Vauban, vers l’est (8). La partie de l'enceinte. entre la tour des Mourgues et le début du rempart tardif ou médiéval, est doublée à l'extérieur par un mur en grand appareil régulier, qui semble devoir être daté du Haut-Empire.

Wheeler, 1926, p. 183-184: Heijmans, 1988, p. 35-36.

19 Pour le problème des murailles, voir aussi: Wheeler. 1926: Benoit. 1934a : Février. 1964: Rouquette. 1987a : Heijmans. 1988. 


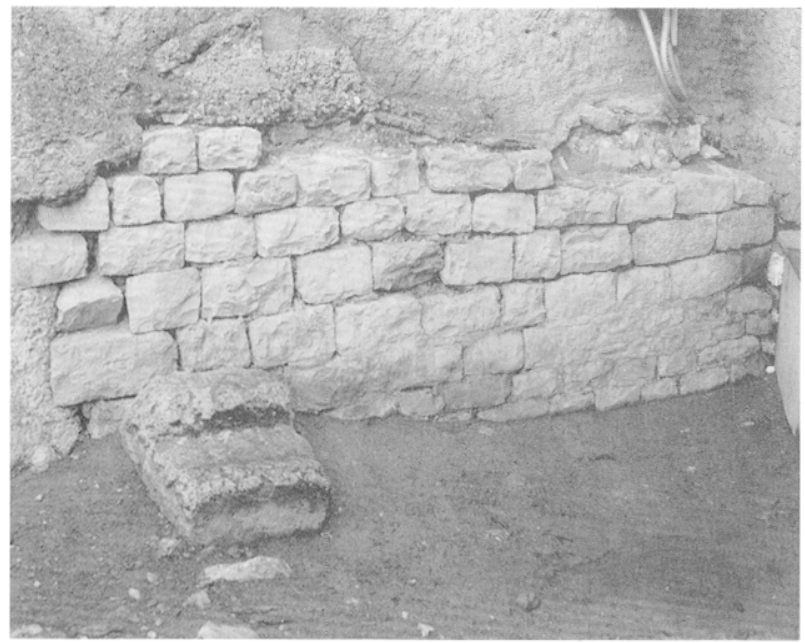

Fig. 8 - Arles au Haut Empire (cf. fig. 6.7).

Fragment de l'enceinte augustéenne, sur le site de l'Esplanade.

\section{Voirie}

Plusieurs portions de voies ont été reconnues anciennement. Dans la quasi-totalité des cas, elles sont construites avec de grosses dalles de calcaire froid, d'une épaisseur de 20 à $50 \mathrm{~cm}$; la plupart des pierres ont des trous de louve pour le levage. Les chaussées comportent généralement un caniveau médian et quelques-unes d'entre elles étaient bordées de trottoirs.

Toutes les rues actuelles du centre-ville présentent la même orientation (nord-sud ou est-ouest) correspondant vraisemblablement au quadrillage datant de l'installation du premier plan d'urbanisme. Seules la voie de l'espace Van-Gogh et celle du Muscon Arlaten ne participent pas de ce quadrillage général : ceci indique peut-être un changement d'orientation pour toute la partie ouest de la ville (le quartier de la Roquette).

- Voie (9).

F.O.R., 136, p. 146.

- Voie du Muséon Arlaten (10).

F.O.R. 111, p. 139.

- Voie de l'Esplanade (11). L'ensemble des thermes fouillé en 1975 est séparé de l'habitat voisin par un cardo bordé de trottoirs, comportant un égout médian. Des massiffs de pierres régulièrement disposées le long de la voie montrent que les trottoirs étaient protégés par un portique. Si l'hypothèse d'un rempart (7) au nord du chantier se confirme, il faut considérer que cette voie était hors des murs.

Gallia. 35, 1977, p. 513-517: 44, 1986, p. 386-390):

Congès. 1987, p. 34 : Congès el alii, 1992, p. 122.

- Fragment du cardo avec trottoir (12). Découvert en 1952 dans une cave, rue de l'Hôtel-de-Ville.

Gallia, XI, 1953, p. 110: Amy, 1973, p. 280.

- Voie de Sainte-Luce (13). Une dalle en calcaire froid. hordée d'un trottoir. a été découverte dans les fouilles de
Sainte-Luce. Quoique l'axe de la voie, en service du fer au IIIC s. après J.-C. environ, soit légèrement décalé par rapport à la trame de la ville, il sagit vraisemblablement de l'extrémité nord du cardo, dont l'extrémité sud a été trouvée dans les fouilles de l'Esplanade.

Gallia. 44, 1986, p. 402.

- Voie de l'hôpital Van-Gogh (14). Cette voie passait le long de la vaste esplanade découverte en 1985 dans l'hôpital Van-Gogh. Elle comporte un égout médian et un trottoir à l'ouest, protégé peut-être par un portique. A l'est se développe la place. La construction de l'ensemble (esplanade, voie et portique) a été datée de la période flavienne. La voie se dirige vers la nécropole du Plan-du-Bourg. le long du cirque (46), et semble faire le lien entre le creur de la ville et ce monument éloigné.

Sintès, 1987b. p. 44: 1992. p. 138: Gallia

Informations, 1987-1988. 2, p. 231-233.

- Esplanade dallée (15) (fig. 9). Découverte dans les fouilles de l'hôpital Van-Gogh, cette vaste esplanade dallée semble prolonger l'espace dallé observé dans les fouilles du Museon Arlaten en 1908 (43). La fouille $\mathrm{n}$ a a pas permis de trouver la limite orientale de cet ensemble mais les dimensions déjà relevées $(35 \mathrm{~m}$ de long au moins par $15 \mathrm{~m}$ de large au moins) montrent l'importance de ce lieu public. La présence de la voie (14) à l'ouest. la proximité des cryptoportiques et de sal place $(\mathbf{4 2})$ rendent difficile l'interprétation qui ferait de cette esplanade un fortum au sens propre du terme.

Sintès 1987b, p. 44-46: 1992. p. 1.38: Ciallia

Informations, 1987-1988, 2. p. 231-233.

- Voie du Trébon (16).

$$
\text { F.O.R.. 41, 43. p. } 147 .
$$

- D'autres voies ont été observées anciennement sur la rive gauche (localisation incertaine).

F.O.R. . 35. 75, 84, p. 147.

- Voies du cimetière de Trinquetaille (17). Le grand monument à portique du cimetière de Trinquetaille est

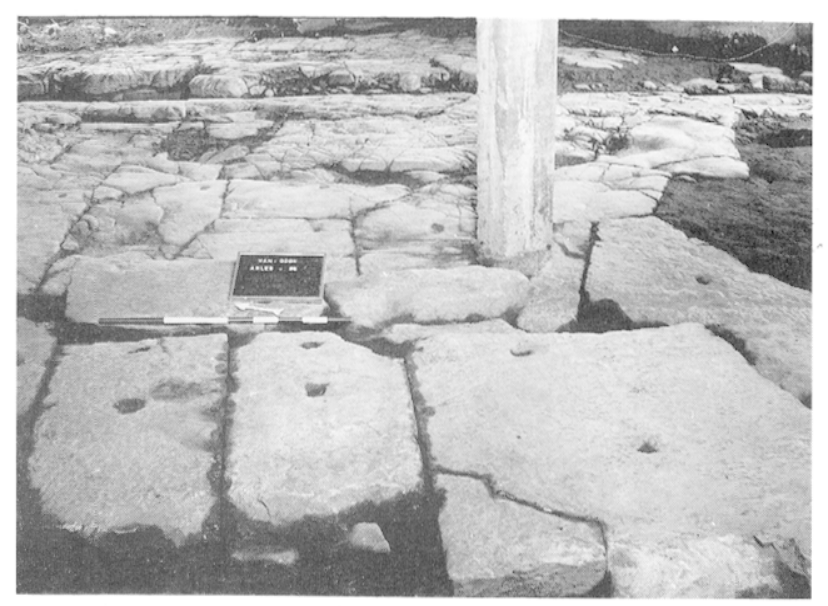

Fig. 9-Arles au Haut Fmpire (cf. fig. 6, 15). Grande place publique, sous l'hôpital Van-Gogh. 
bordé de deux voies formant intersection dans son angle sud-est.

Giallia, 35. 1977, p. 51.3: 44. 1986, p. 397.

- Vestiges d'une voie el d’un bâtiment d’habitation (18).

(jallia Informations. 1990), 1-2, p. 149-150.

- Voic (19).

F.O.R.. 55, p. 175.

- Voie $(\mathbf{2 0})$.

F.O.R., 43, p. 175 .

- Voie dallée avec égout, en direction du Rhône (21). F.O.R., 17, p. 175 .

- Voie (22).

F.O.R., 12. p. 175 .

- Voie (23).

F.O.R., 2, p. 175.

- D’autres voies ont été observées anciennement à

Trinquetaille (localisation incertaine).

F.O.R. 1. 12, 14, 31, p. 175.

\section{Aménagements et \\ franchissements des voies d'eau}

- Quai rive gauche (24).

F.O.R., 133, p. 144.

- Quai rive droite (25).

F.O.R., 51, p. 183.

- Vestiges de quai ? (26). Les structures découvertes ont été identifiées comme quais (traces de planches bien lisibles) mais l'éloignement relatif du bord du fleuve (supposé pour l'époque) rend l'hypothèse fragile. Etude en cours.

- Pont (27). Le fleuve se franchissait par un pont de bateaux (attesté par la mosaïque du forum des Corporations à Ostie et par de nombreuses mentions dans la littérature). La culée de la rive gauche est actuellement en partie noyée sous le quai : il en reste une partie visible dans la vase du Rhône. La localisation sur la rive droite est plus délicate en raison de la présence de vestiges d'ouvrages militaires médiévaux et modernes.

F.O.R., 42, p. 144: F.O.R., 3. p. 175: Daniel. Heijmans. 1992

\section{Adduction d'eau et collecteurs}

- Aqueduc (28).

F.O.R., 24, 25, p. 144

- Embranchement de l'aqueduc (29).

F.O.R., 61, p. 144.

- Aqueduc voûté au sud et à l'ouest de l'amphithéâtre (30).

F.O.R., 84, p. 144.

- Dérivation de l'aqueduc (31).

F.O.R., 86. p. 145.

- Château d'eau - Castellum divisorium - (32). Des observations récentes semblent remettre en cause cette interprétation.

F.O.R., 85, p. 145 : étude en cours.
- Conduite en plomb (33). Les luyaux ont été découverts épars, mais toujours près de la Pointe. La canalisation d'origine aurait dû logiquement franchir le fleuve au même endroit que le pont. mais la plupart des fragments ont été retrouvés bien en ankont de son tracé. F.O.R.. 169. p. 145.

- Aqueduc et fontaine (34).

F.O.R. 101, p. 141.

- Canalisations au sud des cryptoportiques (35).

F.O.R. 110, p. 146: Amy, 1973. p. 280.

- Canalisations du monument à exèdre (36).

F.O.R. 1II. p. 146: Heijmans. 1991. p. 187.

- Egout-collecteur (37). Ce grand égout est-ouest. situé au nord des cryptoportiques, a été reconnu sur $127.50 \mathrm{~m}$ avec plusieurs regards et égouts perpendiculaires. Il devait se jeter à l'ouest dans le grand égout du Méjan.

Heijmans. 1991. p. 18.3-185.

- Grand égout du Méjan (38). Egout-collecteur de grandes dimensions: orienté nord-sud, reconnu anciennement.

F.O.R. 1.35. 136. p. 146.

- Citerne (39).

F.O.R., 67, p. 145.

- Citerne (40).

F.O.R. 53. p. 144.

- Canalisations observées anciennement (localisation incertaine).

F.O.R., 36, p. $144: 87,77,78,95$, p. 146.

- Egouts observés anciennement, leur tracé reste indéterminé.

F.O.R., 1.37, 142, 43, 155, 92, p. 146.

\section{Édifices publics}

- Théâtre (41). Bâtiment participant au premier plan d'urbanisme augustéen et dont la datation (construction de la fin du Ior s. avant J.-C.) a été établic grâce à une étude stylistique des sculptures (découvertes lors du dégagement de ce monument au milieu du XIXes.).

F.O.R. 71, p. 1.32: Formigé. 1948: Gros. 1987. p. $352-356$.

- Cryptoportiques (42). Substructions en forme de fer à cheval qui supportaient la colonnade monumentale entourant le forum augustéen. La construction intervient au même moment que celle du théâtre. c"està-dire à la fin du Ier s. avant notre ère. Un dépotoir de marbre fouillé en 1951 accrédite l'idée de la présence d'un sanctuaire du culte impérial au centre de la place.

Une étude récente amène à l'hypothèse que la galerie des boutiques, au nord des cryptoportiques, serait contemporaine de ceux-ci. Elle donnait probablement sur une place publique plutôt que sur le decumanuss. comme le veut l'interprétation traditionnelle.

F.O.R. 108. p. 138: Benoit. 1951a: 1952b: Amy.

1973: Gros, 1987, p. 352-356: Heijmans, 1991.

- Vestiges du Museon Arlaten (43). Vestiges d'un monument à exèdre fouillé dans la cour de l'Hôtel de Laval-Castellane en 1908. Ce monument a peut-être 


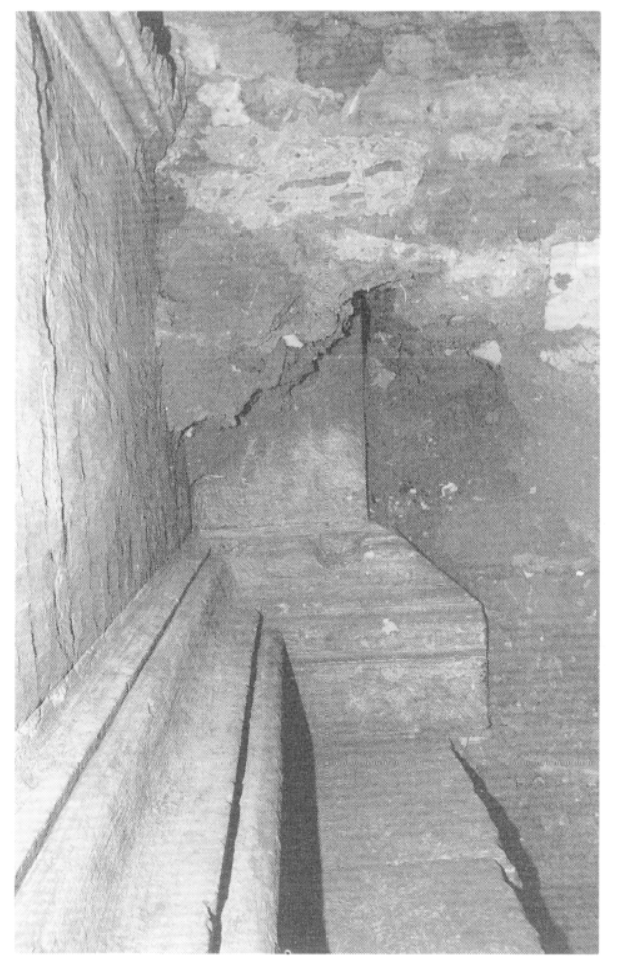

été, plutôt qu'un édifice basilical, une sorte de forum adiectum datable de l'époque tibérienne.

F.O.R., 111. p. 139: Amy, 1973. p. 28.5 : Gros, 1987. p. 357.

- Temple (44). Perpendiculairement à la galerie nord des cryptoportiques a été construit un petit édifice, probablement un temple, dont subsistent des vestiges de l'entablement dans l'hôtel Nord-Pinus. Ce temple est à dissocier des colonnes de la place du Forum, qui ont été rajoutées tardivement.

F.O.R. 109, p. 138-139; Heijmans, 1991, p. 181. 193-194.

- Amphithéâtre (45). Bâtiment daté par les fouilles de F. Benoit de la fin de la période flavienne.

F.O.R. 80, p. 135 : Formigé. 1964/1965.

- Cirque (46). Édifice situé à l'extérieur des murs, à l'ouest de la ville. La datation dendrochronologique des pilotis de fondation montre que le début de la construction est à placer vers le milieu du IIe s. après J.-C. Des embellisements de la barrière et des travaux importants interviennent au moment de la Tétrarchie ou sous Constantin.

F.O.R., 158 à 164, p. 136: Gallia, 44, 1986, p. $394-$ 397: Humphrey, 1986, p. 390): Hallier. 1987: Gallia Informations 1987-1988, 2, p. 234-236: 1990, 1-2. p. 147-149: Sintès, 1992, p. 138.

- Portique (47). Substructions en grand appareil, avec base de colonne, vues lors de travaux à l'intersection des rues du Grand-Prieuré et de Truchet. Cette structure est peut-être à mettre en liaison avec un dallage dominé par un podium, découvert un peu plus vers l'ouest et vers le $\operatorname{sud}(\mathbf{4 8})$.

F.O.R., 130, p. 142.
Fig. $11-$

Arles au Haut Empire

(cf. fig. 6, 53).

Vestiges d'un bâtiment

semi-enterré, rue du

Sauvage, coupe.

- Vestiges d'un bâtiment public, conservés dans des caves le long du Rhône et dans la rue Truchet (48) (fig. 10). Il s'agit d'une construction comportant un stylobate mouluré avec des bases de pilastres engagés, donnant sur un dallage. Le retour de ce podium a été trouvé un peu plus au sud. II pourrait s'agir d'une place entourée d'un portique, peut-être le péribole d'un temple...

Heijmans. Brémond, 1994 : élude en cours.

- Colonnade (49). Une quinzaine de colonnes de granite ont été vues sous la place du Forum. Elles font peutêtre partie de la décoration d'un espace public, au nord des cryptoportiques.

$$
\text { F.O.R., 113, p. } 140 .
$$

- Monument public (50). Monument dont on a vu les substructions et plusieurs colonnes de granite au cours de travaux, en 1972, dans la rue Dieudonné.

Sintès, 1987 c, p. 50.

- Murs (51). Construction préaugustéenne (fig. 1, 1), sans doute réutilisée au cours du Ier s., avec l'édification de murs perpendiculaires en petit appareil.

Gallia Informations, 1990), 1-2, p. 152; Heijmans. Brémond. 1994.

- Fragment de mur en grand appareil, de direction estouest (52).

Gallia, 35, 1977, p. 515.

- Mur est-ouest, percé de soupiraux (53) (fig. 11). En petit appareil, il est surmonté de trois assises en grand appareil et percé de quatre soupiraux au moins, montrant l'existence d'un bâtiment important au nord (édifice semi-enterré avec des lucernaires du même type que ceux des cryptoportiques, quoique d'un module inférieur).

Heijmans, Brémond. 1994 ; ćlude en cours.

- Murs en petit appareil, avec chaînage d'angle en pierre de taille, in situ dans des caves, rue du Sauvage (54).

Heijmans, Brémond, 1994 ; étude en cours. 
- Mur en petit appareil d'un bâtiment public d'orientation nord-sud (55). Ce vestige a été vu lors de la construction d'un immeuble.

Relevés sommaires au musée de l'Arles Antique. Renseignement oral seulement.

- Vestiges de temple (56), quartier de l'Hauture. F.O.R.. 53. p. 1.37.

- Emplacement du temple dit de Mithra (57). Cette interprétation est très aléatoire et repose essentiellement sur la découverte de la statue de Kronos Mithriaque. conservée au Musée d'Arles. F.O.R., 1.57, p. 1.37.

- Temple de la Bonne Déesse (58). F.O.R., p. 138.

- Thermes de la place de la République (59). Les thermes ont été vus lorsque les fondations du socle de l'obélisque ont été creusées en 1675. F.O.R., 99. p. $1+1$.

- Thermes (60). Signalés à l'ouest de l'église des Carmes en 1802 F.O.R.. 10.3, p. 141.

- Thermes de l'Esplanade (61) (fig. 12). Construits sans doute vers la fin du Ile s. ou le début du III' s., le long du cardo. Le complexe thermal semble détruit à la fïn du IIJ's.

Congès, 1987, p. 36 : Congès et alii, 1992. p. 125-126. 131.

- Piédestal (62). Dans une cave. rue du Sauvage, piédestal (ou fontaine) protoaugustéen, avec murs et canalisations.

Gallia Informations. 1990, 1-2, p. 152-153: Sintes. 1992, p. 135.

- Arc du Rhône (63). Arc démoli en 1684. Les dessins conservés, entre autres dans le portefeuille de Natoire et dans la collection Sautereau, ont permis de dater ce monument du Haut-Empire. L'inscription sur l'entablement de la façade a été attribuée à Constantin : la difficulté de lecture des documents graphiques du XVIIC s. fait que cette interprétation est douteuse.

Une étude récente contredit l'interprétation de F. Benoit. (arc quadrifrons). L'arc marquait peut-être le départ d'un pont sur le Rhône, antérieur au pont de bateaux plus à l'est.

Benoit. 1929: F.O.R.. 141. p. 130: Von Gladiss,

1972. p. 19-27: Böhm. 1992. p. 24-43.

- Arc Admirable (64). Arc de triomphe détruit au Moyen Age et qui devait son nom à un décor remarquable.

F.O.R., 36. p. 130: Böhm. 1992, p. 92-112.

- Mur en grand appareil (65) d'orientation nord-sud. observé anciennement. Une mosaïque (non décrite) est signalée à côté du mur, rendant l'interprétation délicate : s'agit-il d'un bâtiment privé de grandes dimensions, d'un bâtiment public au sol mosaïqué ?...

F.O.R.. 147. p. 143.

- Grand bâtiment à portique (66) découvert dans le cimetière de Trinquetaille. Les fouilles ont montré que

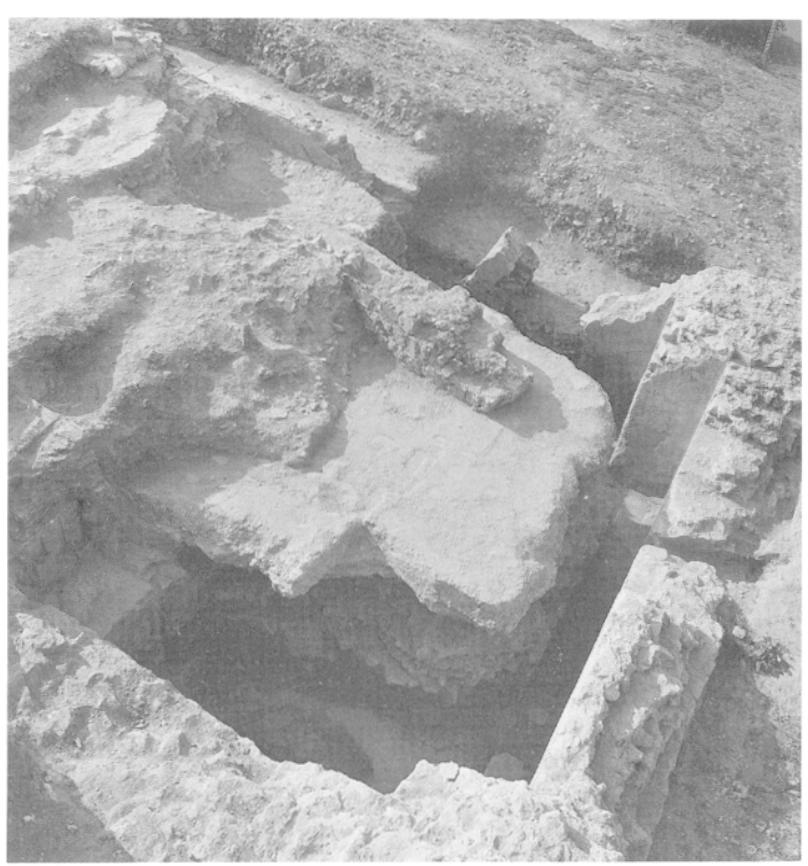

Fig. 12 - Arles au Haut Empire (cf. fig. 6, 63). Thermes de l'Esplanade.

ce bâtiment était bordé par deux voies dallées et avait un usage lié à l'activité commerciale et portuaire du secteur.

Benoit, 1938b, p. 541-546: Gallia, 30, 1972, p. 514 : 32. 1974. p. 509: 35. 1977, p. 513: 44, 1986. p. 397 : Rouquette. 1989, p. 14.

- Bâtiment public (67).

F.O.R.. 9, p. 180.

- Vestiges de temple (68).

F.O.R.. 56, p. 183.

\section{Habitat}

Le nombre important de fouilles d'habitat fait que l'on n'a pas numéroté cette section. On pourra se reporter aisément à la bibliographie (p. 168) et plus particulièrement, outre la F.O.R. (Benoit, 1936), à :

Benoit 1934 b et c : - pour les fouilles et les découvertes anciennes aux Informations de Gallia 35. 1977 et 44. 1986: à Gallia Informations. 1987-1988, 2; 1990. 12: à Dampeine, 1980): Rouquette. 1980): Sintès (ed.). 1987: - pour les fouilles récentes à Sintes 1989a et c: 1992.

\section{Commerce et artisanat}

- Atelier du Crédit Agricole (69). Des grandes dalles avec des saignées et des traces d'usure peuvent avoir constitué un fond de pressoir. L'installation des maisons a complètement bouleversé cet établissement du Jer $s$.

Rouquette. 1987b. p. 71.

- Des structures de type artisanal (70) ont été découvertes sur le site de l'I.R.P.A. : plusieurs indices laissent supposer que cette activité est liée à la construction du cirque.

Sintès. 1990a. p. 12-13: Gallia Informatioms, 1990, 12. p. 145-146: étude en cours. 


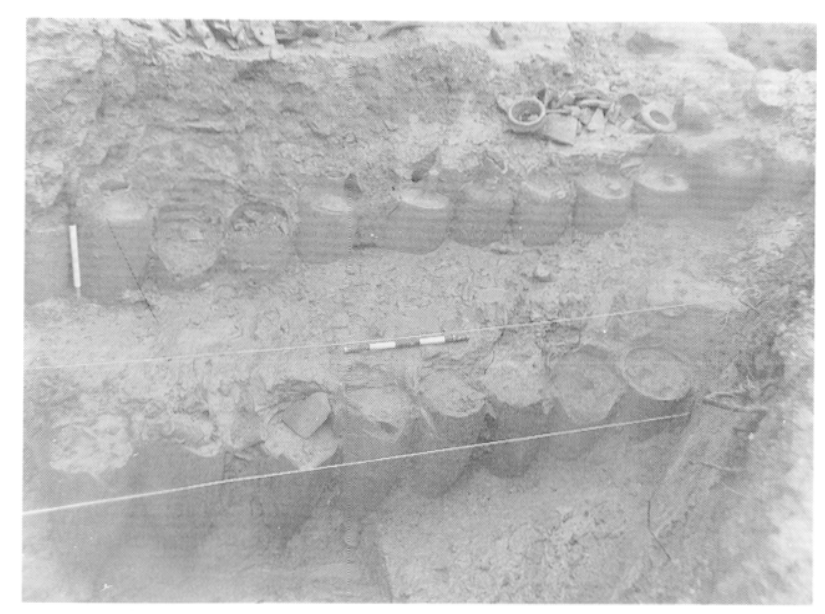

Fig. 13 - Arles au Haut Empire (cf. fig. 6. 73). Ile des Sables, rangées d'amphores enterrées.

De nombreuses traces d'activités artisanales marquent le caractère commercial renforcé de la rive droite :

- Docks (71). Vestiges de murs et de structures pouvant faire penser à des aménagements (entrepôts, docks) le long du Rhône.

Benoit. 1944at. p. 254.

- Docks (72). Edifice militaire, "docks et arsenal des légeions de Césarar", d'après F. Benoit.

Gillia, VI, 1948, p. 209.

- lle des Sables (73) (fïg. 13). Les travaux de préparation du chemin de fer de Lunel en 1866 ont amené la mise au jour d'importantes substructions, interprétées comme docks.

A l'occasion d'une fouille plus récente, ont été découverts des aménagements de grande ampleur réalisés avec des amphores plantées en lignes. enserrant des bassins de bois. L'activité, qui semble artisanale ou agricole, n'a pas encore été élucidée.

F.O.R.. 2. p. 176: (jallia Informations. 1990) 1-2. p. 149.

- Vestiges de docks? (74). Plusieurs centaines d'amphores, alignées, s'avançant dans le Rhône. F.O.R., 4. p. 177.

- Dépôt d'amphores (75). Très nombreuses et apparemment rangées. elles étaient peut-être stockées dans un entrepôt.

Information orale: quelques amphores au muscé de l'Arles Antique.

- Atelier de céramique? (76).

F.O.R. 4. p. 177.

- Magasin avec amphores (77).

F.O.R., 30, p. 181.

- Dépotoir de poteries (78). Certaines, «très grandes, paraissent être des ratés provenant peut-être d'une fabrique locale». F.O.R., 50, p. 183.
- Atelier de potier (79). Substruction de four (?) et ratés de cuisson observés lors de la construction d'un caveau dans le cimetière de Trinquetaille.

Renseignement oral: matériel au musće de l'Arles Antique.

- Atelier de céranique (80). De nombreux tessons semblant être des ratés de cuisson ont été remontés lors de la construction du pont en 1971.

Renseignement oral : matériel dispersé et perdu.

- Zones de rupture de charge $(\mathbf{8 1 , 8 2})$. De très nombreuses amphores entières ont été récupérées dans le Rhône: ceci tendraient à montrer la présence d'une rupture de charge à cet endroit.

Prospection 1989 du Département des Recherches Archéologiques Sous-Marines (D.R.A.S.M.) : matéricl conservé au Musée de l'Arles Antique.

\section{Funéraire}

11 est bien difficilc de sc fairc une idée de la configuration des nécropoles arlésiennes. De manière classique elles occupent les terrains proches des voies d'accès (c'est-à-dire les cordons alluviaux entourés de marais). en encadrant la ville sur les deux rives du fleuve. mais il est bien délicat de dire, comme cela a pu être suggéré parfois, que ces sépultures finirent par former un anneau sans solution de continuité. Il semble plutôt que l'espace se soit divisé en zones denses alternant avec des champs, des jachères, parfois même des habitations.

Seule une étude fïne pourra faire comprendre pourquoi, par exemple, en plein coeur des Alyscamps. des zones sont abandonnées pendant trois siècles alors qu'au même moment, dans le jardin d'Hiver, on inhume dans l'espace laissé libre par la destruction d'un habitat ${ }^{20}$.

- Enclos funéraire et mausolée (83). Découvert en 1970, lors de l'achèvement du nouveau canal d'Arles à Fos. Le mausolée dont on a retrouvé les substructions a été restitué grâce aux éléments de placage et du décor de marbre (G. Hallier). Les rinceaux permettent de proposer une datation voisine du milieu du ler s. après J.-C.

Euzennat, Hallier, 1987, p. 114-116.

20) Comme pour l'habitat. nous n'avons pas numéroté les découvertes funéraires. L'ensemble des découvertes anciennes est donné dans F.O.R., p. 156-164 (Arles) el p. 184-189) (Tringuetaille). Pour le laut-Fmpire, les fouilles récentes ont concerné :

- la nécropole du cirque romain : (iallia, 30, 1972, p. $516: 44$. 1986, p. 397: - Euzennat, Hallier. 1987. p. 144-116:Gallia Informations, 1990). 1-2, p. 146 :

- les franges de la nécropole des Alyscamps : Rochefleur, ef. Sintès. 1987i :

- pour un élat de la question. voir : Sintès, 1987g. 
- Mausolées du cirque (84). Série de mausolées et denclos funéraires, fouillés sur l'emplacement du musée de l'Arles Antique (I.R.P.A.). et datable des Il" et III's.

Sintès. 1990)a. p. 13-15: (iallia Informations. 1990) 1$\therefore$ p. 146 : ćlude en cours.

- Edifice (85). Relevé au centre de la nécropole de la Pointe, il peut être assimilé à un monument funćraire (mausolée?).

F.O.R. 37. p. 184.

- D'autres mausolées ont été signalés aux Alyscamps et près du cirque, mais l'imprécision des données (orales ou trop anciennes) fait que l'on ne peut cartographier ces éléments.

\section{ARLES AU IVe $\mathbf{S}$.}

\section{ÉVOLUTION TOPOGRAPHIQUE (fig. 14)}

Le IVcs. est traditionnellement considéré pour Arles comme une seconde période de splendeur. voire même comme un apogée. Ce moment particulièrement rayonnant serait dû à la faveur des empereurs de la famille de Constantin.

L.A. Constans considère Arles comme résidence impériale dès 308, mais la documentation n'est pas asse\% abondante pour permettre d'être aussi affirmatif?' En fait, le seul séjour certain de l'empereur se place en $316^{22}$. Deux lois sont promulguées à Arles au cours de ce sćjour ${ }^{23}$

C'est en honneur de Constantin II, né à Arles probablement au début de l'année 317. que le nom de la ville se transforme en Constantina, nom qui apparât en 328 sur les monnaies frappées à Arles depuis 313. Le nom disparaît en 340). après la mort de l'empereur. mais quelques années plus tard (en 35.3) le nom change à nouveau. légèrement transformée cette fois: la ville sappelle désormais Constantia, en thonneur de Constance qui passait l'hiver de 353-354 a Arles2t.

La richesse et la splendeur de la ville pour le IVes. apparaissent aussi dans Ausone. qui place Arles au deuxième rang des villes gauloises après Trèves ${ }^{25}$, et dans un texte anonyme. l'Expositio totius mundi ${ }^{26}$.

Dans les deux cas, cest surtout la fonction commerciale. Arles port fluvial et maritime, qui est soulignée. Ausone, d'autre part. décrit la situation topographique en parlant très précisément de «ville

21 Constans, 1921. p. 99-100).

$22 \mathrm{Cl}$. pour une étude eritique des donneses historiques: Féricer. 1978. p. 146-149.

23 Code. Theodesiamus. XI, 30, 5, 6.

24 Cf. P.V. HIII. R.A.G. CARSON. J.P.C. KI:NT, Laler Roman Bronze Coinage A.D. 32t-498. Londres 1960) p. 9. 54.

25 Al'sone. Ordo Urbium Nobilium. 73-80).

26 Expositio totius mundi et gentium, LVII. double», duplex Arelas ${ }^{27}$. Il semble bien que pour lui Trinquetaille était. dans la seconde moitié du IV“ s.. un quartier habité.

Le IVés. est enfin la période où la topographie chrétienne s’installe : comme ville commerciale. Arles a sans doulc connu assez tôt une communauté chrétienne: le premier évêque. Marcianus. est attesté dès $254^{28}$ et c'est à Arles que se tiendra le premier grand Concile d'Occident où, en 314, on débat sur le donatisme: c'est le début de la primatie de l'église d'Arles en Gaule ${ }^{29}$.

De ces trois aspects, la présence des empereurs. la survie de l'habitat à Trinquetaille et la naissance de la topographic religieuse. on retrouve des traces dans la documentation archéologique. bien que l'inventaire reste plutôt décevant.

L’édifice le plus célèbre est le complexe. attribué à Constantin, des thermes du Nord près du Rhône. mieux connu sous le nom de thermes de Constantin, ou même palais de Constantin. La tradition y voyait en effet le palais que lempereur avait construit et où Constantin II était né30.

Depuis le déblaiement effectué au début du siècle. on sait qu il s’agit de thermes. sans doute publics. Rien n'empêche de penser que ce sont des thermes palatiaux. mais aucun élément ne permet de l’affïrmer. Les limites du complexe ne sont pas comnues : on en perd trace au sud du restaurant «Le Constantin», où la façade orientale s"appuie contre une construction antérieure (fïg. 6, 54). Encore un peu plus au sud a été trouvée une abside monumentale, qui a certainement fait partie. à un moment donné, de l'ensemble thermal, mais qui se distingue très nettement par son appareil. Ici, sur plus de $10 \mathrm{~m}$ d’élévation, aucune arase de brique n’est visible. La fouille récente invite à la dater plutôt du V's.

Dans l'Hôtel d'Arlatan et les maisons voisines, sont conservés, parfois largement en élévation, des pans de murs semblables avec de larges baies qui ont également été interprétés comme faisant partie des thermes. Une élude en cours a permis d individualiser ce bâtiment. dont les éléments reconnus pour le moment (édifice rectangulaire de plan basilical) se prêteraient mieux à une interprétation d'aula palatina.

En plus des éléments actuellement reconnu près des thermes, il faut signaler une tour plus au sud-ouest qui subsiste encore en élévation, mais qui est peu accessible. Ici. le décroûtage des murs a permis de

27 A part le texte de l'Orde. déjà cité. Ausone parle encore deux fois de ce double aspece de la ville: Mosella. 480-481 et Epistular. XXIII, $81-82$.

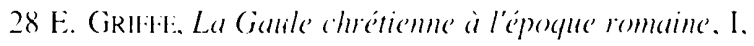
Paris 1964. p. 62-93.

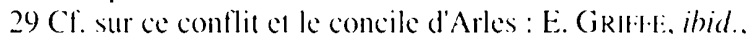
p. $186-200$.

30) Ainsi cncore Véran. 19()4. 


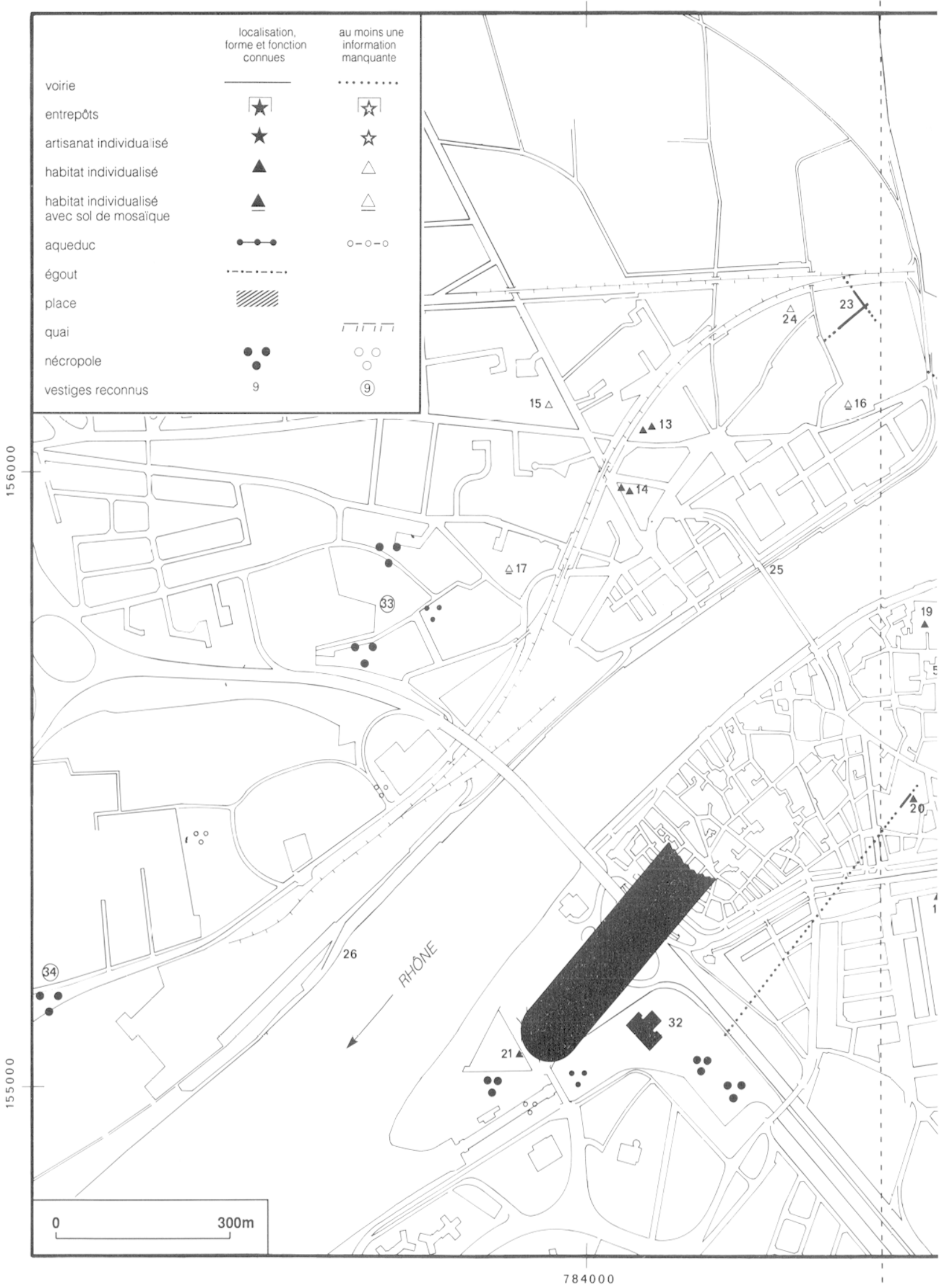




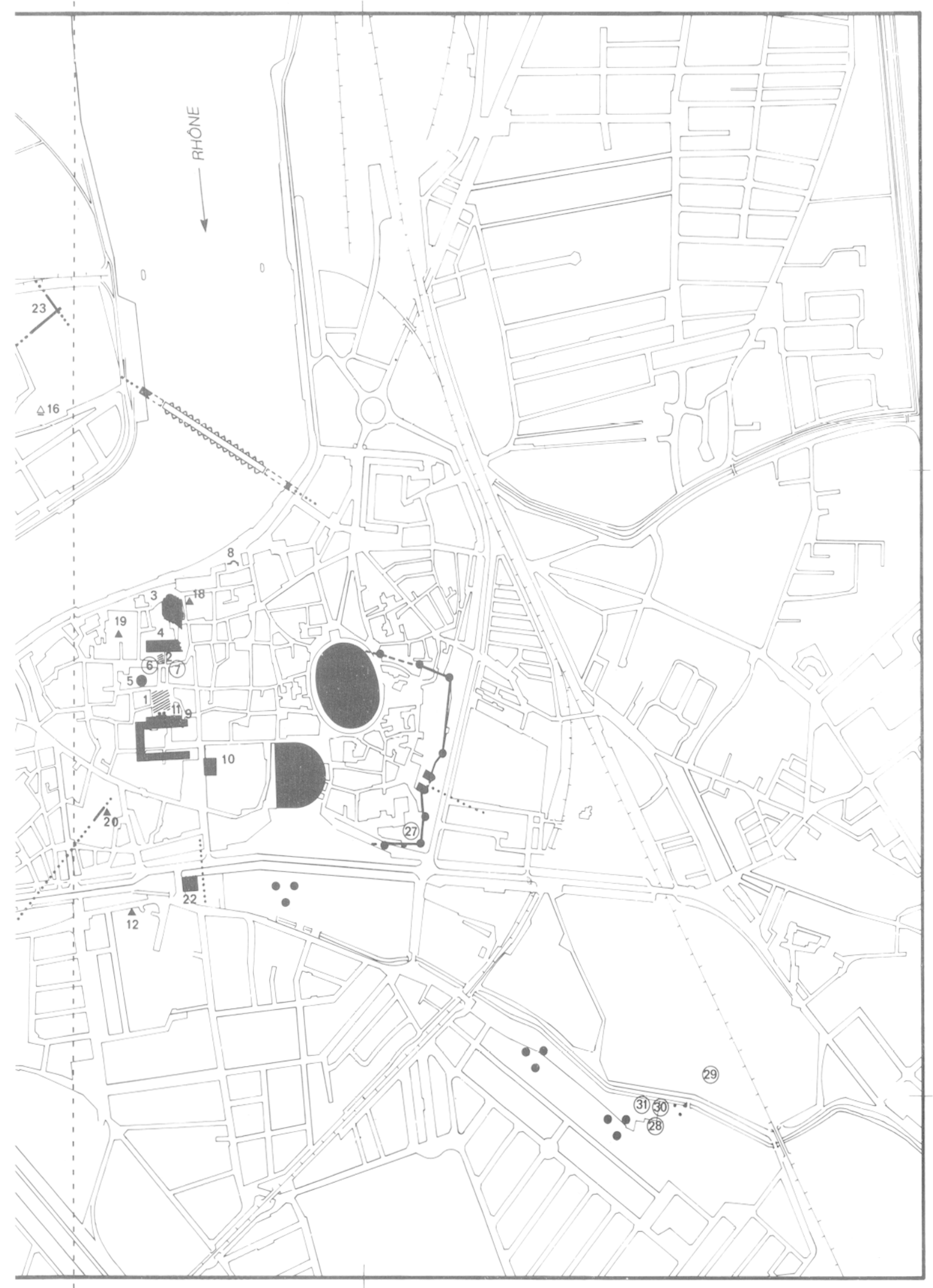

785000

Fig. 14 - Plan 3: Arles au IV"s. 
mettre au jour trois grandes baies, avec des briques dans les claveaux. Dans l'élévation du mur, les briques manquent toutefois et il est actuellement impossible de donner une interprétation à cette tour, qui ne semble pas avoir été la seule : un manuscrit anonyme retrouvé à la fin du XIXes. au Cairc ct offert à la bibliothèque d'Arles en mentionne d'autres, visibles au milieu du sièle dernier ${ }^{3 !}$.

Une autre construction attribuable à la réorganisation du centre-ville sous Constantin est la galerie à arcades au nord des cryptoportiques, qui s'ouvrait devant les boutiques, probablement sur une place publique, et était dominée par le grand bâtiment public dont nous sont parvenues deux colonnes surmontées d'un demifronton. Une inscription a été lue sur l’architrave grâce aux trous dencastrement des lettres: elle est généralement attribuée à Constantin II. La datation de cet ensemble (galerie et inscription) est des plus douteuses : la lecture de l’inscription est loin d’être sûre et l'usage de briques dans les voûtes et les murs de la galerie ne doit pas obligatoirement faire croire à une construction constantinienne. La façade du temple d'autre part doit être contemporaine de la galerie : si elle est datée stylistiquement du Haut-Empire, il faut conclure qu il s"agit de réemplois.

C'est encore à Constantin que l'on attribue l'inscription, conservéc par des dessins et des gravures du XVIIC s.. qui a été lue sur l’arc du Rhône. appelé aussi arc de Constantin. Daté du Haut-Empire (fig. 6 , 63), lare aurait donc eu une nouvelle dédicace: la documentation reste cependant trop pauvre pour accréditer cette interprétation.

Un autre bâtiment qui semble devoir être daté du IVC s., grâce à son appareil à arases de brique, a été fouillé récemment à l'est des thermes de Constantin. Une abside orientée au nord pourrait faire partie de thermes publics : ce bâtiment, totalement inattendu à cet endroit en raison de la proximité des thermes de Constantin, n’a pas pu être daté précisément car les couches archéologiques en connexion étaient gravement bouleversées par la construction toute proche du rempart médiéval. L’appareil de l’abside, bien que présentant des arases de brique, est cependant différent de celui des thermes de Constantin.

Reste enfin la construction conservée sous la première travée de la nef de l’église Saint-Trophime. Quatre murs est-ouest, reliés par des voûtes plus récentes, sont construits en petit appareil ; dans les arcs des baies ouvertes dans ces murs, on retrouve des claveaux formés par la juxtaposition de grandes tuiles plates. La construction de basse époque semble certaine. mais préciser la datation est actuellement illusoire.

Si l’on se tourne vers l’habitat privé. la documentation est aussi bien maigre. A Trinquetaille,

31 Anonyme du Caire, BMArles, MS 744. p. I01. on sait que des destructions générales, ou du moins très étendues, affectent le quartier dans la seconde moitié du III's.

A la suite de ces destructions, certaines pièces de riches maisons des $\mathrm{II}^{\mathrm{C}}$ et $\mathrm{III}^{\mathrm{C}} \mathrm{s}$. sont réutilisées, parfois restaurées grossièrement vers la fïn du IV et au V゙s. Les fouilles du chantier de la Verrerie et de la rue PicrreBrossolette ont montré une réoccupation sporadique d'un caractère pauvre au milieu d'un quartier en ruines. Le même phénomène a été observé dans une fouille plus ancienne près de la route de Fourques.

Bien qu une étude stylistique propose de dater du IVes. certains pavements de mosaïque retrouvés à Trinquetaille, il faut rester sceptique quant à une occupation générale par des habitats luxueux à cette époque.

Les autres activités connues à Trinquetaille pour le IV's. sont rares. En dehors des nécropoles, sur lesquelles on reviendra, on peut tout au plus noter la présence d'un dépotoir à l’intérieur du grand bâtiment fouillé dans le cimetière de Trinquetaille, dépotoir daté de la charnière fin IIIC - début IVe $s$.

Sur la rive gauche, le phénomène de l'occupation sporadique, après la destruction du IIIC s.. se retrouve. Ainsi. sur le chantier du Crédit Agricole, une villa, détruite vers 250, est réoccupée partiellement, mais sans le même caractère luxueux, jusqu'à la seconde moitić du IV's.

C’est également vers la fïn de ce siècle qu’apparaît le phénomène de l'occupation parasitaire des monuments et places publiques, comme au cirque ou sur l'esplanade flavienne de l'hôpital Van-Gogh, phénomène qu'on verra se développer au $V^{e} s$.

Cet exemple montre bien que l'on ne connaît pas encore d’habitations privées, datées sûrement du IV's., dont le luxe puisse égaler celles, fort nombreuses, des $\mathrm{II}^{\mathrm{C}}$ et III' $\mathrm{s}$. découvertes à Trinquetaille et au sud de la ville. On est donc en droit de se demander où a pu habiter la riche élite arlésienne dont l’existence est assurée par l’impressionnante série de sarcophages en marbre conservée dans les musées d'Arles. Il est difficile d'imaginer que ces hommes puissants aient pu continuer à vivre dans un quartier en partie ruinć. Il faut donc soit imaginer de grands quartiers réorganisés aux $I V “$ et $V^{c}$ s. et dont nous n'avons pas encore trouvé trace, ou bien des propriétés foncières situées en Camargue, en direction des Alpilles, vers la Crau, assez. éloignées de la ville. Malheureusement. jusqu à ce jour, aucune fouille ne vient confïmer ce début d'hypothèse.

Le troisième aspect de la topographie arlésienne au IVes., la topographie religieuse, est lui aussi peu maîtrisé. On a déjà parlé de l’ancienneté de l'église d'Arles et du Concile de 314. Rien ne permet de dire où ce concile s'est tenu: on peut seulement déduire des textes plus tardifs l'existence d’un groupe épiscopal avec un vieux baptistère au sud-est de la ville. là où saint Césaire fondera plus tard son monastère de femmes. 
En dehors de ce groupe épiscopal, on ne connaît aucun édifice chrétien à l'intérieur des murs pour la période qui nous intéresse.

A l'extérieur de la ville, en revanche. certaines des vastes nécropoles païennes ont donné naissance aux nécropoles paléochrétiennes. 32. C'est le culte du martyr saint Genest qui a attiré une foule de tombes ad sanctos autour de ses deux lieux de vénération. Genest, jeune greffier du III's. ayant essayé d'échapper aux soldats romains, traversa le Rhône mais fut décapité à Trinquetaille avant d'être ramené sur la rive gauche pour être enterré aux Alyscamps. Dès le début du IVe s., la zone proche de la tombe présumée de Genest était particulièrement vénérée ${ }^{33}$.

C'est surtout autour de la chapelle Saint-Honorat, dont le pèlerinage a remplacé celui de saint Genest au XIIE s., que le plus grand nombre de sarcophages a été trouvé. mais la zone cimétériale était de vaste étendue (les sarcophages découverts au Jardin d'Hiver le confirment).

Malheureusement, l'origine exacte des sarcophages trouvés aux Alyscamps est souvent inconnue et la datation très difficile à établir surtout pour les pièces non sculptées. Autour de Saint-Honorat et. en général, aux Alyscamps, de nombreuses chapelles sont connues. Trois édifices dont l'appareil présente des arases de brique peuvent être vus comme relevant d'une époque ancienne, avec toutes les réserves d'usage quant à la datation donnée par l'appareil seul.

De l'autre côté de la ville, près du cirque romain, la nécropole semble avoir fonctionné jusqu à la fin du IVe s. sans témoignage proprement chrétien. L'abandon de la nécropole se situe au même moment que l'apparition de l'habitat tardif: ils n'ont donc pas coexisté. Il est aussi probable que le grand mausolée à rotonde, attribué un peu rapidement à Constantin III, doive plutôt être daté du IVes.

La nécropole de Saint-Genest-de-Trinquetaille, d'une richesse moins grande que celle des Alyscamps, a quand même livré bon nombre de sarcophages datables du IVe s. et des deux siècles suivants. L'étendue en était sans doute fort grande comme le montre la découverte des trois sarcophages en marbre du IVC s., près des papeteries Étienne à l'ouest de Trinquetaille. Des circonstances difficiles ont empêché les observations précises pendant la fouille, mais le grand nombre de tombes et la présence de murs (mausolée ?) prouvent qu 'il ne s'agit pas d'un phénomène isolé.

Le manque d'information permet, tout au plus, de dire que la nécropole des Alyscamps et celle de SaintGenest-de-Trinquetaille ont laissé une série impressionnante de sarcophages justement réputés, qui

32 Cf. en général sur les nécropoles chrétiennes d'Arles: Benoit. 1935a.

33 Cf. sur le culte de saint Genest à Arles ct ailleurs : Benoit, 1935a, p. 4-12.

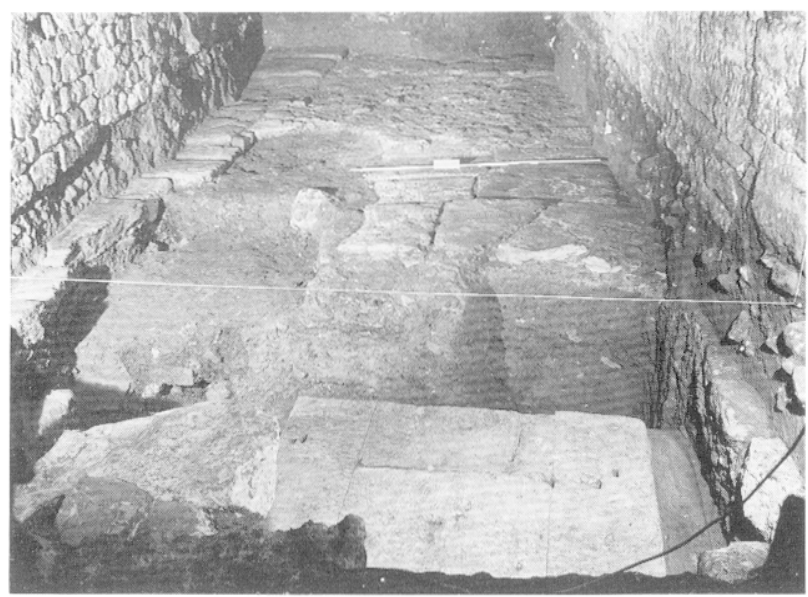

Fig. 15 - Arles au IVe s. (cf. fig. 14, 2).

Dallage tardif, recouvrant le piedestal augustéen.

témoigne de la richesse de l'élite arlésienne du IV“ et du début du Ve s. ${ }^{34}$

\section{REPÈRES TOPOGRAPHIQUES}

\section{Voirie}

- Place au nord des cryptoportiques (1). A-t-elle fait partie des réaménagements du centre-ville?

Constians. 1921. p. 258-261: F.O.R. 113. p. 140.

- Dallage (2) (fig. 15). La fouille dans une cave de l'Hôtel d'Arlatan a mis au jour un dallage en calcaire tendre, avec une occupation des IVe et Ve's.

Gallia Informations. 1990), 1-2, p. 153.

\section{Édifices publics}

- Thermes du Nord, dits de Constantin (3). Vaste établissement thermal. dont seule la partie nord est conservée en élévation. Le bâtiment se prolonge vers le sud dans les maisons de la rue du Sauvage. La limite occidentale est pour l'instant inconnue.

F.O.R.. 120, p. 141: Grenier, 1960, p. 256-26.3:

Gallia. 30. 1972, p. 514-516: 32, 1974, p. 507:

Ileijmans. Brémond. 1994 : étude en cours.

- Grand bâtiment de type basilical. peut-être une cula a palatina (4) (fig. 16). Le bâtiment est conservé en élévation dans l'Hôtel d'Arlatan et les maisons voisines.

F.O.R., 124. p. 141 : étude en cours.

- Tour en petit appareil, avec briques dans les claveaux des baies (5) (fig. 17). Un mur, signalé par F. Benoit dans une cave voisine, fait partic de cette tour.

F.O.R., 113. 125. p. 142 : ćlude en cours.

34 Benoit. 1954 : - P.-A. FI:VRII:R, La sculpture funéraire à Arles au IV" el début du $V^{c}$ s.. in : XXI corso di cultura sull'arte ravemate et bizamina. Ravenna $5-1.5$ marzo 1978. Ravenna 1978. p. 159-181. 


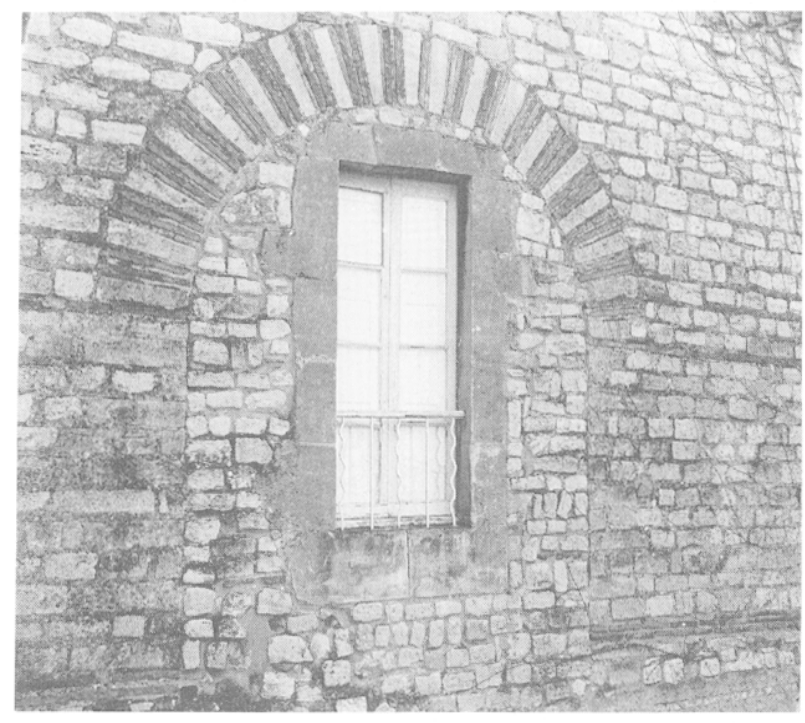

Fig. 16-Arles au IVE s. (cf. fig. 14.4).

Mur en élévation dans l'Hôtel d'Arlatan; faisait peut-être partie d'une aula palatina.

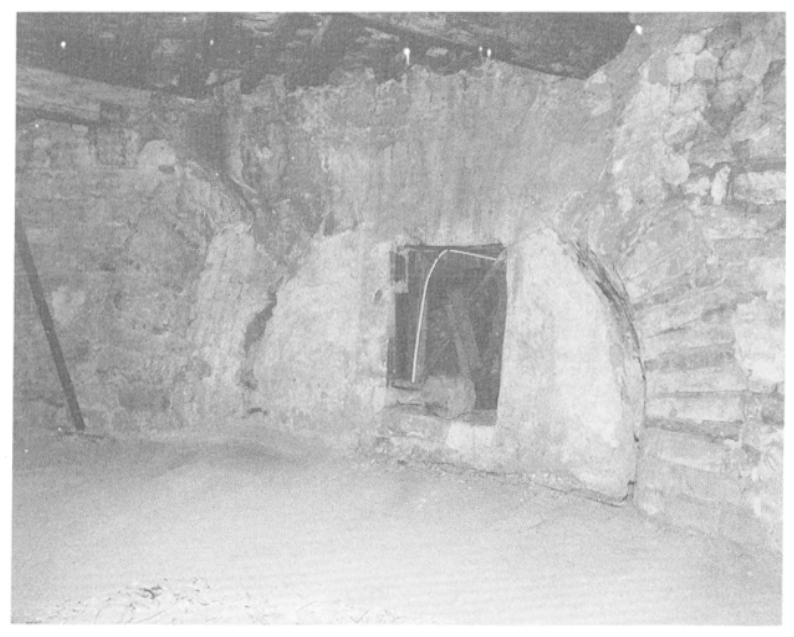

Fig. 17 - Arles au IV's. (cf. fig. 14, 5).

Baies d'une tour conservée dans la rue de la Liberté.

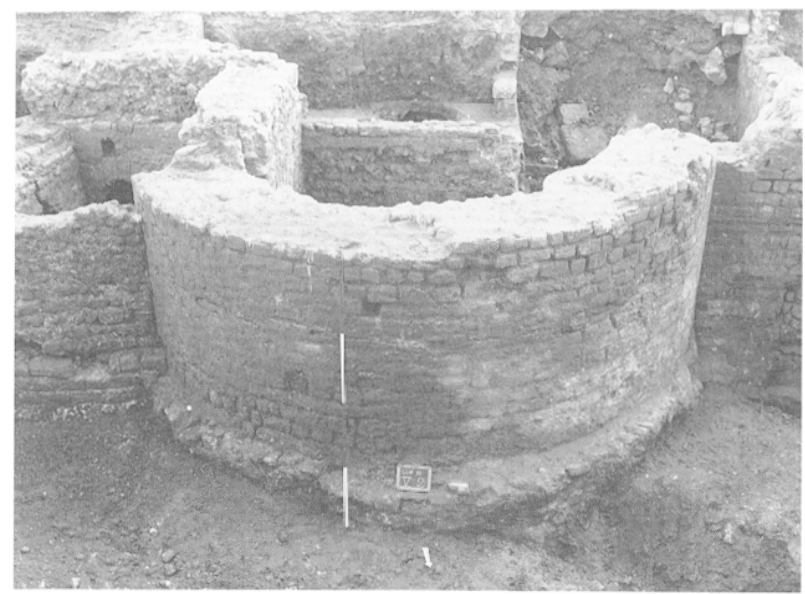

Fig. 18-Arles au IV's. (cf. fig. 14, 8). Abside de thermes, place Suarès.
- Tour identique, disparue (6). Il s’agit peut-être de la même tour que 5 .

F.O.R. 126. p. 142.

- Vestiges de murs, disparus (7).

F.O.R., 127. p. 142.

- Abside (8) (fig. 18). Probablement faisant partie des bains froids de thermes fouillés sur la place AndréSuarès.

Gallia Informations. 1990). 1-2. p. 150.

- Cryptoportiques (9). Aménagement d'une galerie à arcades au nord des cryptoportiques.

Constans, 1921, p. 259-261: Amy. 1973, p. 283-284: Heijmans, 1991. p. 181-182 el 195-196.

- Chambres voûtées sous l'église Saint-Trophime (10). F.O.R., 104, p. 140-141: Rouquette, 1974a, p. 286288 ; ćtude en cours.

- Façade du temple sur la place du Forum (11). Cette façade doit être contemporaine de la galerie à arcades (9). sur laquelle elle repose. Il s'agit probablement de réemplois. L'inscription est généralement attribuée à Constantin II.

CIL XII, 668 ; F.O.R., 109, p. 138-139; An.Ep. 1954, 37: Heijmans. 1991, p. 193-196.

\section{Habitat}

- Villa du Crédit Agricole (12). Réoccupation sporadique jusqu’à la seconde moitié du IVe $s$. Gallia. 44, 1986. p. 394 ; Rouquette. 1987b, p. 77.

- Chantier de la Verrerie (13). Réoccupation sporadique vers la fin du IVes. de quelques pièces d'une habitation du Haut-Empire.

Gallia, 44, 1986. p. 399 : Sintès, 1987f, p. 84.

- Chantier de la rue Pierre-Brossolette (14). Réoccupation sporadique de quelques pièces d'une habitation du Haut-Empire et réaménagements tardifs. Gallia Informations. 1987-1988. 2. p. 237.

- Villa de la route de Fourques (15). Restaurée au BasEmpire. Gallia, VIII, 1950, p. 122.

- Villa de Saint-Pierre-de-Gallèque (16). Une mosaïque est datée (stylistiquement) du IVes.

F.O.R., 6. p. 179-180; Dampeine. 1980, $\mathrm{n}^{\circ} 53$.

- Villa du Clos Saint-Jean (17). Mosaïques datées daprès $F$. Benoit du IIIe s. et d'après M. Dampeine du IVes.

F.O.R., 47, p. 182 : Dampeine, 1980, n 76-77.

- Autres habitats observés :

- Commanderie de Sainte-Luce. Sol en béton de tuileau du IVes. (18).

Étude en cours.

- Traces d'habitations dans l'église des Prêcheurs (19). Mur et foyer datables de la fin du IVe et du début du Ves.

Étude en cours.

- Début de l'habitation sur l'esplanade fouillée sous I'hôpital Van-Gogh (20).

Sintès. 1987b. p. 44-45: Gallia Informations. 1987 1988. 2. p. 233 : Sintès. 1994. 
- Début de l’habitation parasitaire du cirque dès la fin du IVes. (21).

Gallia Informations, 1987-1988. 2, p. 236: 1990. 1-2. p. 146-147: Sintès, 1990a. p. 15, 59-62: Sintès. 1994.

- Thermes de l'Esplanade des Lices (22). Ils sont pillés par des chaufourniers qui y campent jusqu`à 380 environ.

Congès, 1987, p. 37 : Congès et aiii, 1992. p. 126 127 : Sintès, 1994.

- Chantier du cimetière de Trinquetaille (23). Dépotoir de la fin du IIIe et début du IVe s. : l'utilisation des voies perdure.

Gallia, XXV, 1967, p. 400-402: XXVII, 1969. p. 421 : 44, 1986, p. 397 : Piton. 1988.

- Taius de la Gare Maritime de Trinquetaille (24). Sol du Bas-Empire avec de la céramique constantinienne.

Gallia, VIII, 1950, p. 122.

\section{Commerce et artisanat}

- Zones de rupture de charge (25, 26). De très nombreuses amphores entières, datées du Bas-Empire entre autres, ont été récupérées dans le Rhône : ceci tendrait à montrer la présence d'une rupture de charge à cet endroit.

Prospection 1989 du Département des Recherches Archéologiques Sous-Marines (DRASM).

\section{Édifices religieux - nécropoles}

- Groupe épiscopal d'origine - vieux baptistère et ecclesia - (27). Ni la localisation, ni la datation exactes ne sont connues.

Février, 1986, p. 80, n¹.

- Lieu supposé de la tombe de saint Genest (28) entourée d'une nécropole ad sanctos. L'existence d'une chapelle au IV's. est présumée, sans preuve archéologique ou littéraire. Des fouilles anciennes ont mis au jour une partie de l" "area", à l'ouest de la chapelle, avec une grande quantité de tombes. La fouille, plus récente, de la crypte Saint-Honorat a montré l'existence d'une nécropole tardive, mais seul un mur peu datable semble être antérieur au XII's.

Benoit. 1938a: 1944b: 1947: 1952: Gallia. VIII.

1950. p. 119-120: XI. 1953.p. 107-108: Février.

1986, p. 8.3. n० 1.3: Gallia Informations, 1990, 1-2. p. $150-152$.

- Chapelle Saint-Bertulphe (mausolée ?) (29). Bâtiment à arases de brique, démoli en 1844 .

Constans, 1921, p. 395-399: F.O.R. 14. p. 143.

- Chapelle Saint-Polycarpe (30). Construction à arases de tuile.

F.O.R. 16. p. 142.

- Chapelle Saint-Trophime (31). Construction à arases de tuile.

F.O.R., 16. p. 142.

- Mausolée près du cirque romain. dans la nécropole du Plan-du-Bourg (32), daté de la seconde moitié du IVe ou du début du Ves. La fouille récente sur le site de
I’I.R.P.A. a livré une grande quantité de tombes datables du IVes.

Euzennat. Hallier. 1987. p. 117 : Gallia Informations. 1990. 1-2. p. 146.

- Chapelle Saint-Genest à Trinquetaille (33). Lieu présumé du martyre de saint Genest et centre d'une nécropole paléochrétienne importante : aucune preave n'existe pour cette chapelle au IVes. La nécropole est par contre très bien attestée.

Benoit, 1934b, p. 210-216: 1935a. p. 28-31: Gallia.

XXII. 1964. p. 575-576: Février. 1986. p. 84. nº 14.

- Mausolée (34). Découverts en janvier 1974. les trois sarcophages en marbre étaient probablement placés dans un mausolée dont subsistent des murs et le sol.

Rouquette. 1974b.

\section{ARLES AUX Ve - VIe s.}

\section{ÉVOLUTION TOPOGRAPHIQUE (fig. 19)}

A Arles, le Ves. commence par un fait politique important: le transfert de la Préfecture des Gaules depuis Trèves et l'installation de l'Assemblée des Sept Provinces en $418^{3.5}$. Le texte qui règle cette installation. l'Imperatoris Honorii Constitutio. comporte une description élogieuse de la ville où Arles est décrite comme un centre commercial prospère ${ }^{36}$. Quoique composé dans un style exubérant qui caractérise la chancellerie du Bas-Empire, le document montre l’importance d'Arles au début du Ves. : au VI’ s.. le pont d'Arles est encore réputé ${ }^{37}$.

Avec raison, on considère souvent Arles comme le dernier bastion de la civilisation latine ${ }^{38}$. Pendant que le reste de la Gaule était aux mains des Wisigoths, depuis longtemps pour certaines provinces, Arles demeurait romaine jusqu en 476, moment où les troupes des rois wisigoths s'emparèrent de la ville.

En 508, après la bataille de Vouillé. Théodoric, roi des Ostrogoths en Italie, libère Arles assiégée par les Francs et les Burgondes. Sous ce prince, la Préfecture

35 La date du transfert n'est toujours pas assuréc. Voir J.R. PALANOL I: La date du transferl de la préfecture des Gaules de Trèves à Arles, REA, XXXVI, 1934, p. 359-365: - A. Chastagiol. Le repli à Arles des services administratifs gaulois en l'an 407 de notre ère. Rer. Hist. 1973, 23-40):- J.R. PAI.ANQur: Du nouveau sur la date du transfert de la Préfecture des Gaules de Trèves à Arles ?. Pror. Hist., XXIII. 1973, p. 29-38:- E. Di:molgigot, La Notitia Dignitatum el I'histoire de l'empire d'Occident au début du V's.. Latomus. 34. 1975, p. 1(179-11.34 et plus particulièrement les pages 1091 a 1093:- Cl. SinTr:s. La réutilisation des espaces publics à Arles.... Antiquité tardive, 2, 1994.

36 Imperatoris Honorii Consitutio. ed. Monumenta Germaniac Historica. Epist. IlI. p. 13-1.5.

37 CASSIOLORI: latidue. VIII. 10, 6

38 L'expression est de L.A. Constans (1921, p. 105). 


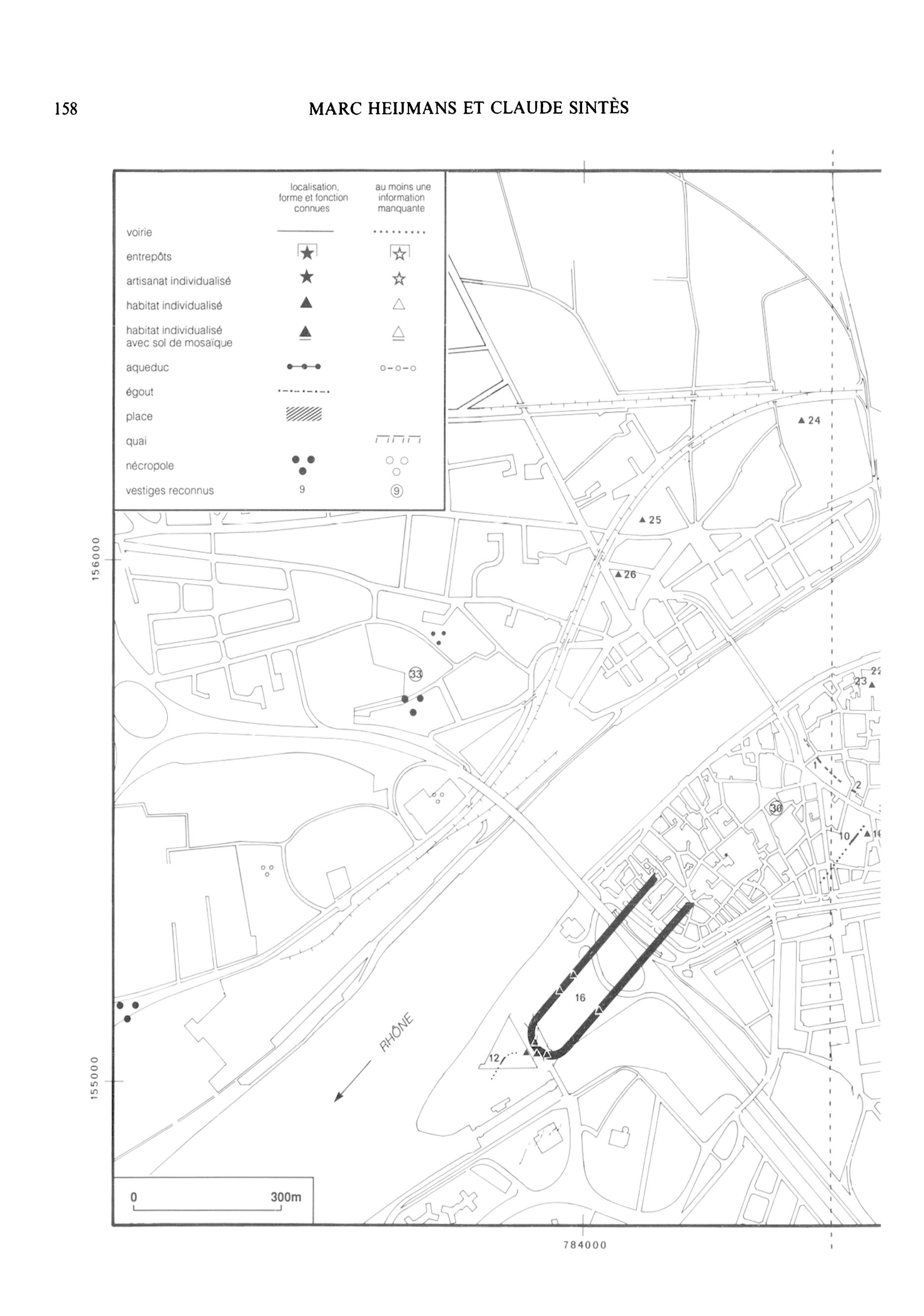




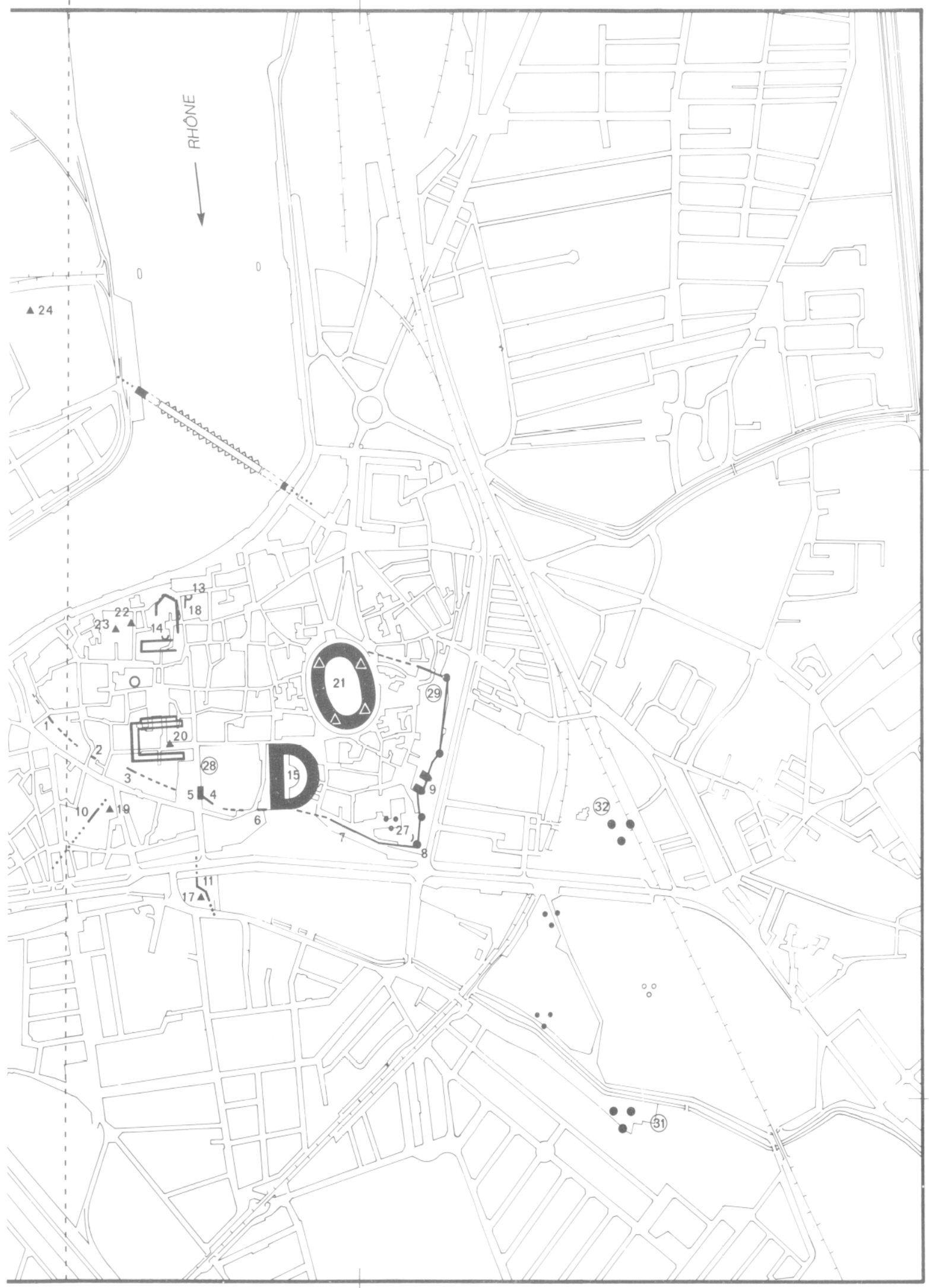

785000

Fig. 19-Plan 4 : Arles aux V̌-VI゙s. 
des Gaules est restaurée et la vie à la romaine continue: on sait que Théodoric a également fait restaurer les remparts de la ville ${ }^{39}$. En 536, Arles est livrée aux Francs, mais ceux-ci n’ont jamais porté trop d'attention à la Provincia lointaine, le centre politique et économique étant au nord de la Gaule.

Un autre fait non négligeable est l'épidémie de peste du milieu du VI's. qui cause la mort d'une grande partie de la population en Gaule du Sud, comme dans le reste du monde méditerranéen ${ }^{40}$.

En ce qui concerne la suprématie pour le domaine religieux. le Ves. est marqué par la lutte entre Arles et Vienne. C'est l'Eglise d'Arles qui l'emportera grâce à une série d’évêques énergiques, dont les plus connus sont: Honorat (426-43()), Hilaire (430-449) et, au VIC's., Césaire (503-542). C'est grâce à leur pugnacité et à leur rayonnement qu'Arles devient au cours du Ves. l’Eglise la plus importante des Gaules ${ }^{+1}$.

Comme souvent. la topographie d’Arles connue à ce jour ne donne qu'un vague reflet des faits historiques. Le problème le plus grave, et certainement le plus débattu, restc la construction d'une enceinte réduite en grand appareil, édifiée presque essentiellement avec des pierres de remploi arrachées aux monuments proches du tracé.

Les éléments littéraires et l'observation de ces murailles sont une aide bien faible et l'on peut imaginer sa construction aussi bien à une date basse (IXe s. par exemple) qu“à une date haute (postéricure toutefois au milieu du Vle s. s`il faut tenir compte de la datation de la fondation de la basilique des Saints-Apôtres «à l'intéricur des murs", a l'endroit de la future église paroissiale de Sainte-Croix, au Bourg-Vieux).

Pour les voies, on connaît deux tronçons en utilisation aux Vé et VI's. : à l’hôpital Van-Gogh. la voie dallée d'époque flavienne est recouverte par une chàssée en terre battue qui reprend la direction d'origine et qui est réparée et rechargée fréquemment jusqu’à son abandon à la fïn du VIIC ou au début du VIIIe s., voire même jusqu à l'époque où les Trinitaires s”installent à cêt endroit. au début du XIII ${ }^{\circ}{ }^{42}$.

Un autre chemin en terre battue a été découvert sur le chantier de l'Esplanade: il ne suit pas le cardo. mais se dirige vers le sud-est en direction des Alyscamps. Le quartier semble totalement abandonné dès le Vlés.

La construction publique civile paraît assez pauvre pour cette période. On a simplement relevé l'abside fouillée à Sainte-Luce, orientée au sud et datée du Vé ou

39 CASSIODORI: lariar. III. 44.

40 Cf. J.-N. Birabin et J. Le Gorf, La peste dans le Haut Moyen Age, Annales, Eronomies. Sociétés. Civilisations, 24, 1969. p. 1484-1510.

41 Cf. E. Griliti. La Ganle chrétienne à l'époque romaine. II. Paris, 1966, p. 146-164.

42 N. Rivil:Rl: Les Trinitaires, in : Sintès (ed.). 1987. p. 43 . du VI's. Au sud des thermes du Nord se trouve une grande abside, appartenant à une piscine froide. Elle a été rajoutée au complexe thermal (probablement au Vés.), mais semble déjà abandonnée dès le siècle suivant.

Pour l'habitat privé, les fouilles récentes ont apporté quelques éléments inattendus : l'occupation, par des maisons d'un type assez frustre, des espaces et des bâtiments publics, occupation dont on a vu les premières traces dès la fïn du IVes.

Par ailleurs, les fouilles en cours au cirque romain ont montré que les alvéoles sous les gradins étaient systématiquement occupées dès l'extrême fin du IVes. ou au début du Ve s. et ce jusqu’au milieu du VIE s., au moment où le grand monument est détruit. Les fouilles plus récentes de l'I.R.P.A. ont précisé que l'espace situé devant chaque alvéole a lui aussi été occupé. formant un petit corps de logis avancé. Enfïn. quelques installations se trouvent un peu au-delà, mais n'empiètent pas sur la nécropole qui est bien séparée de l'habitat par un long mur. On a trouvé aussi les restes d'une voie en cailloutis, de direction sud-ouest, parallèle au Rhône et qui scelle des inhumations du IVes.

A l’Esplanade, une maison est construite au début du Vés.. à l'est du cardo, sur les ruines d’une maison du Haut-Empire. Cet habitat tardif sera à son toutr détruit par l"installation du chemin en terre battue.

Encore plus près de la ville et peut-être à l'intérieur des murs, des maisons s“installent directement sur le dallage flavien de l’hôpital Van-Gogh, à côté de la voie en terre battue. Ici aussi. l'habitat apparaît dès la fin du IVes. et se poursuit jusquau milieu du VÍ s.. ce qui donne à peu de choses près des datations contemporaines de celles de l'habitat du cirque.

Des sondages, de surfaces plus réduites, ont permis d'observer ce même phénomène dans l'église des Frères Prêcheurs, où une partic de l'importante structure le long du Rhône. (figg. 1, 1 : fig. 6, 51 ) a été récupérée. pour laisser la place à un mur avec un foyer. Non loin de là, le dallage d'une place du Haut-Empire (fig. 6, 48) est utilisé pour constituer le sol d'un habitat.

Enfin, au-dessus des cryptoportiques, un habitat prend possession du dallage du fortum augustéen dans la seconde moitié du Vés.

Il est certain qu'une partie du stylobate, et donc de la colonnade, était détruite au moins à cet endroit. Si l'on prend en compte le texte de Sidoine Apollinaire qui parle, à la fin du Ve s., du forum avec ses colonnes ${ }^{43}$. on est obligé de se demander si le formm se trouvait bien au-dessus, ou s'il faut restituer une autre place, au nord des cryptoportiques par exemple.

Au même moment, les galeries sont également occupés. Une étude récente du matériel trouvé en

43 Epistulae. I, 11, 7-8. 
connexion avec le fameux dépotoir de marbre (probablement le stock d'un chaufournier), qui a été mis au jour lors du déblaiement de la branche nord au début des années 50, montre qu'il peut être daté du début du Vés.. comme le témoin du plancher dans la galerie sud qui remonte à la même période.

Reste enfin un point très délicat. Le très grand nombre de monnaies du Ve s. trouvées aux arènes qui. bien que l'on n'en connaisse pas la provenance exacte, a fait dire à certains qu'un habitat est venu se greffer dans cet édifice de spectacles, comme au cirque.

Il n'est pas sans intérêt de noter qu'un autre bâtiment public, le théâtre antique, commence à être pillé systématiquement dès le milieu du Vés., sans doute avec l'accord du pouvoir civil, pour procurer des matériaux de construction nécessaires à l'édification de la basilique.

On retrouve ce type d'occupation parasitaire, sur l'autre rive, à Trinquetaille. Ainsi, au cimetière, le dépotoir du IVés. est scellé par un niveau tardif du $V e$ s. et dans certaines villac, fouillées récemment (Brossolette, Verrerie), on aperçoit les traces d'une fréquentation et même des aménagements de pièces jusqu'au début du VIrs.

Ce phénomène des habitations parasitaires occupant certains bâtiments et espaces publics semble apparaître (bien que les datations puissent encore être affinées) quasiment au même moment partout.

Est-ce que cette croissance soudaine de la population est due à l'afflux des réfugiés du nord de la Gaule, qui ont suivi la protection de la préfecture des Gaules lors de son transfert depuis Trèves à Arles, (et pour l'accueil desquels le pouvoir politique aurait mis a disposition des bâtiments publics?), ou bien les gens ont-ils cherché une protection améliorée auprès des remparts. attirés par la prospérité économique de la ville ?... Toutes les hypothèses sont possibles en l'absence de renseignements d'ordre littéraire. Tout au plus peut-on noter qu'il s'agit, dans la plupart des cas, et malgré la découverte de monnaies d'or dans une case du cirque, de constructions modestes ${ }^{44}$.

Les hypothèses expliquant la disparition de cet habitat extra-muros, qui se produit là aussi à peu près partout au même moment. c'est-à-dire dans la seconde moitié du VIe s., sont fragiles : a-t-on cherché refuge à l'intérieur d'une enceinte réduite plus sûre? La population a-t-clle diminué à cause de la peste qui règne à cette époque...?

La topographie religieuse d'Arles aux Ve et VIc s. a toujours suscité beaucoup de commentaires grâce aux très nombreuses informations littéraires d'ailleurs plutôt qu'aux fouilles qui sont très pauvres. Au IVe s., on a noté la présence du groupe épiscopal au sud-est de la ville. C'est probablement dans la première moitié du

$44 \mathrm{Cl}$. pour une dernière mise au point de ce problème : Sintès, 1994.
Vés. que ce siège est transféré vers le centre-ville à la place de l'actuelle église Saint-Trophime.

De cette première église. il ne reste plus de trace visible. Entre les voûtes des chambres dont on a parlé (fig. 14, 10 ) et le sol de l'église actuelle, se trouvent les restes d'une mosaïque et de deux dallages qui pcuvent chacun appartenir à un des états de l'église antérieur au XIes.

La première cathédrale était dédiée au proto-martyr Étienne qui restera l'un des patrons de la primatiale. jusqu'au moment où les reliques de saint Trophime seront transférées des Alyscamps jusque dans la nouvelle cathédrale construite au XIe s.

II n'empêche que l'endroit où s'élevait l'écclesia primitive, dans l'angle du rempart, restait un lieu sacré. C'est ici que Césaire fonda un monastère de femmes avec une triple basilique dédiée à Sainte-Marie. SaintJean-le-Baptiste et Saint-Martin.

A l'intérieur de l'enclos du monastère se trouvaient des chapelles dont on ne connaît que les noms. C'est à l'une de ces chapelles qu'a dû appartenir l'abside découverte par F. Benoit, près du rempart augustéen. Les églises Saint-Jean-de-Moustiers et Saint-Blaise ont été édifiées au XIIC s. sans doute à l'endroit des anciens édifices, voire sur l'emplacement même de la basilique. sans que l'on puisse trouver des éléments de réponse dans les anciennes fouilles. Tout au plus, sait-on qu'une grande quantité de tombes a été découverte au XIXes. à l'intérieur de Saint-Jean-de-Moustiers et que la tombe de saint Césaire, détruite puis restaurée, était jusqu'aux temps modernes encastrée derrière le maître autel de l'église Saint-Blaise.

Les citernes dont parle la Vie de saint Césaire ont peut-être été retrouvées près des remparts au cours des fouilles de F. Benoit : il est en tout cas impossible de dire si les colonnes et les autres fragments d'architecture exhumés au même moment ont appartenu aux bâtiments de l'abbaye ou s'ils sont plus anciens.

Au nord-est de la ville, se trouve l'église NotreDame-de-la-Major. Une inscription médiévale, perdue, date sa fondation de 453, sous l'épiscopat de Ravenius et le consulat d'Opilio et de Vincomalus au cours d'un synode. Cette inscription est unanimement considérée comme fausse mais on sait qu'à l'occasion d'un concile à Arles en 524, une basilica sanctae Mariae fut consacrée au moment du consulat en Occident d'un certain Opilio! Hasard? Confusion ? Il faut rester très prudent car les éléments sont bien maigres.

La confusion devient encore plus grande avec les fondations religieuses de l'évêque Aurélien. Il fonda probablement en 547 un monastère d'hommes avec une basilique in honore sanctorum Apostolorum. Ce monastère est dit intra-muros, or il ne peut y avoir de doute, cet établissement était à l'origine de l'église Sainte-Croix dans le Bourg-Vieux.

Ce même évêque installa un autre monastère, cette fois-ci de femmes, également à l'intérieur des murs. La 
localisation du bâtiment avec sa basilica sanctac Mariae est inconnue ${ }^{45}$.

Ainsi, on trouve au milieu du VIe s. à l'intérieur des remparts (en dehors du groupe épiscopal) au moins trois monastères avec au moins deux et peut-être trois églises dédiées à Sainte-Marie et une autre dédiée aux Saints-Apôtres. La Vie de Césaire fait aussi mention d'une autre basilique des Apôtres où l'évêque avait une demeure et qu'on ne saurait identifier avec celle du monastère d'Aurélien ${ }^{46}$; en outre la Vie de saint Hilaire mentionne une basilica Constantia, nommée peut-être d'après Constance au début du Ve ${ }^{4}{ }^{47}$. Enfin, dernier mystère, Césaire fut quelques temps abbé d'un monastère in suburbana insula. Au Moyen Age, ce terme désigne l'île de Cappe, environ $3 \mathrm{~km}$ au sudouest de Trinquetaille ${ }^{48}$. Le monastère de Césaire se trouvait-il ici? Plus près de Saint-Genest? On ne saurait le dire.

Dans la nécropole des Alyscamps, le culte du martyr Genest s'est développé. Une basilica beati Genesii a sans doute remplacé assez tôt la chapelle primitive qu'il faut imaginer là. Le lieu est toujours aussi réputé pour les inhumations mais la série de sarcophages en marbre datés du IVes. ne semble pas se continuer au-delà du début du Ves. Hilaire, par exemple, est inhumé dans un sarcophage païen en remploi.

En l'absence d'éléments très précis. il est difficile de voir l'évolution de la nécropole et donc de lui donner une limite: tout au plus, peut-on dire que certaines zones semblent abandonnées, comme au Jardin d'Hiver où une partie de la nécropole du IVe s. ne paraît pas avoir été utilisée aux Ve et VIe s., tandis que plus au nord, au-delà de la voie de chemin de fer, de nombreux sarcophages datés des Ve et VIc s. se trouvent dans des lieux où l'on n'inhumait pas au IVe s.

Autour de la hasilica sancti Petri et Pauli, fondée avant 530, a été trouvée une quantité importante de sarcophages et d'inscriptions, datés du début du VIe s. Notons enfin, que les sarcophages trouvés plus récemment à Rochefleur et datés du VIe s. par la stratigraphie ont été installés dans une zone qui n'avait pas encore connu d'inhumations ${ }^{49}$.

La seconde nécropole paléochrétienne du IVes., celle de Saint-Gencst-de-Trinquetaille. est également encore en usage durant le Ve et même le Vle s. Près des sarcophages trouvés en 1974, une fouille rapide a mis au jour un grand nombre de tombes tardives, peut-être mérovingiennes ${ }^{50}$.

La nécropole du cirque au Plan-du-Bourg est-clle aussi utilisée au Ves. ? En plus de quelques tombes

45 Février, 1986, p. $83, n^{\circ} 12$.

46 Février, 1986, p. 82. n 99.

47 Févricr. 1986, p. 81, n 5.

48 Février, 1986, p. 84, n 15.

$49 \mathrm{Cf}$. Sintès, $1987 \mathrm{i}$.

50 Cf. sur ces tombes, datées uniquement sclon le type d'inhumation : Sintès, 1987k.

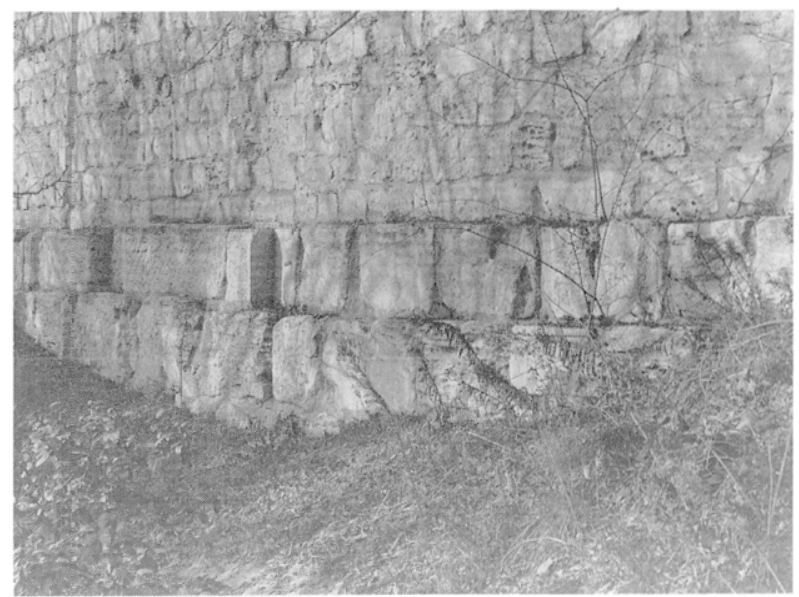

Fig. 20 - Arles aux Ve-VIe s. (cf. fig. 19.9).

Fermeture de la Porte de la Redoute.

modestes, peu datables, un grand mausolée y est découvert en 1970), daté de la seconde moitié du IVes. ou du début du Ve s. Ce bâtiment, inachevé, a conduit les fouilleurs à y voir un mausolée destiné à l'usurpateur Constantin III. au début du Ves. Bien que cette interprétation soit séduisante. les indications sont pauvres et il est plus probable qu'il s'agisse du mausolée monumental d'une famille puissante.

\section{REPÈRES TOPOGRAPHIGUES}

\section{Enceinte}

- Mur en grand appareil, découvert dans une cave de la rue Jouvène (1).

Etude en cours.

- Mur en grand appareil (2). Des travaux récents ont permis d'observer ce mur sur une longueur d'environ $4 \mathrm{~m}$.

F.O.R., 138. p. 128. Heijmans, 1988, p. 27.

- Rempart tardif dans la cour de l'Hôtel de LavalCastellane (Museon Arlaten) (3).

F.O.R. 112. p. 128. Heijmans, 1988. p. $27-29$.

- Rempart (4). Ce mur est mitoyen entre le palais de l'Archevêché et l'ancien Hôtel des Postes.

F.O.R. 97. p. 140): (iallia. XII. 1954. p. 429: Heijmans. 1988, p. 29-32.

- Porte Saint-Etienne (5). Devant la façade du mur 4. se trouvait au Moyen Age la porte Saint-Etienne. détruite en 1810. La description donnée semble devoir la faire appartenir à cette période. mais une construction postérieure peut être aussi envisagée.

F.O.R. 98. p. 132. Heijmans, 1988. p. 29-32.

- Fragment de mur à l'ouest du théâtre (6).

F.O.R. 65, p. 129. Heijmans. 1988, p. 31.

- Mur tardif de la montée Vauban (7). De très nombreux fragments architecturaux en remploi ont été retrouvés dans le mur. lors de sa destruction au XIXes.

F.O.R., 62-64, p. 128-129. Heijmans, 1988. p. $32-33$. 
- Tour des Mourgues (8). Le côté nord. à l'extérieur. présente un appareil semblable aux autres murs tardifs.

F.O.R. 50. p. 127. Heijmans. 1988. p. 36-37.

- Porte de la Redoute (9) (fig. 20). Fermeture de la porte par des gros blocs, à une époque indéterminée mais probablement antérieure au XIc s. Ces travaux participent peut-être de la construction d'une enceinte tardive.

Heijmans. 1988, p. 37-40.

\section{Voirie}

- Voie en terre battue de l'hôpital Van-Gogh (10). Utilisée jusqu'au début du VIIIC s.

Sintès, $1987 \mathrm{~b}$.

- Voie en terre battue du chantier de l'Esplanade (11). En direction du sud-est, elle fut utilisée pendant les VeVIes.

Gallia. 44, 1986, p. 389-391: Congès, 1987, p. 37 : Congès ct alii. 1992. p. 128: fouilles en cours.

- Voie en cailloutis à l'I.R.P.A. (12), venant du cirque et longeant le Rhône.

Elude en cours.

\section{Edifices publics}

- Abside sous l'Hôtel de Sainte-Luce (13). Orienté au sud, ce bâtiment est daté des Ve- VIe s. par la céramique trouvée en connexion.

Gallia. 44. 1986, p. 402.

- Abside d'une piscine froide. en place dans une cave, rue du Sauvage (14). Cette abside faisant partie des Thermes du Nord a probablement été construite au V's. et abandonnée au VIe s.

Heijmans. Brémond. 1994 : étude en cours.

- Théâtre antique (15). Récupération des pierres et des marbres du théâtre dès le milieu du Ve $s$.

Sintès. 1989b. p. 26-29.

\section{Habitat}

- Habitats (16) (fig. 21). Ils occupent les alvéoles du cirque romain, de même que l'espace immédiatement extérieur. Cet habitat s'installe à l'extrême fin du IVe ou au début du Ve s. et disparaît au milieu du VIe s. en même temps que le cirque. Le puits situé plus à l'ouest, dans la cour du local artisanal du Haut-Empire, est toujours utilisé comme point d'eau à cette époque.

Gallia. 44, 1986, p. 397 : Sintès 1987e, p. 64-65:

Gallia Informations, 1987-1988, 2. p. 236: 1990. 1-2. p. 146-147: Sintès. 1990a. p. 15, 59-62: Sintès. 1994 : fouilles en cours.

- Maison à l'est du cardo sur le site de l'Esplanade (17). Cet habitat est construit au début du Ve s. et abandonné peu après la construction de la voie en terre battue (11).

Gallia. 44, 1986, p. 389-391 : Congès, 1987, p. 37 :

Congès et alii. 1992, p. 127-128: fouilles en cours.

- Maison avec cour et seuil. fouillée sur le site de Sainte-Luce et datable du Ve s. (18).

Gallia. 44, 1986, p. 402.

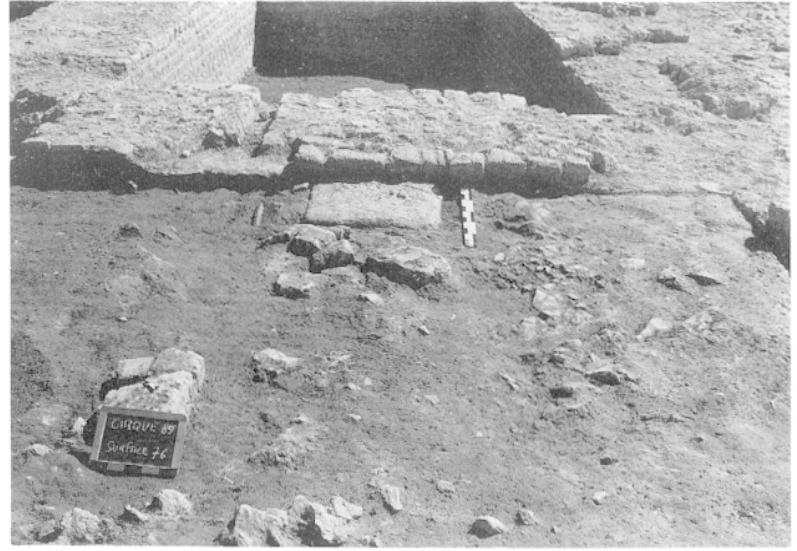

Fig. 21 - Arles aux Ve-VIes. (cf. fig. 19, 16).

Habitats parasitaires dans les alvćoles du cirque.

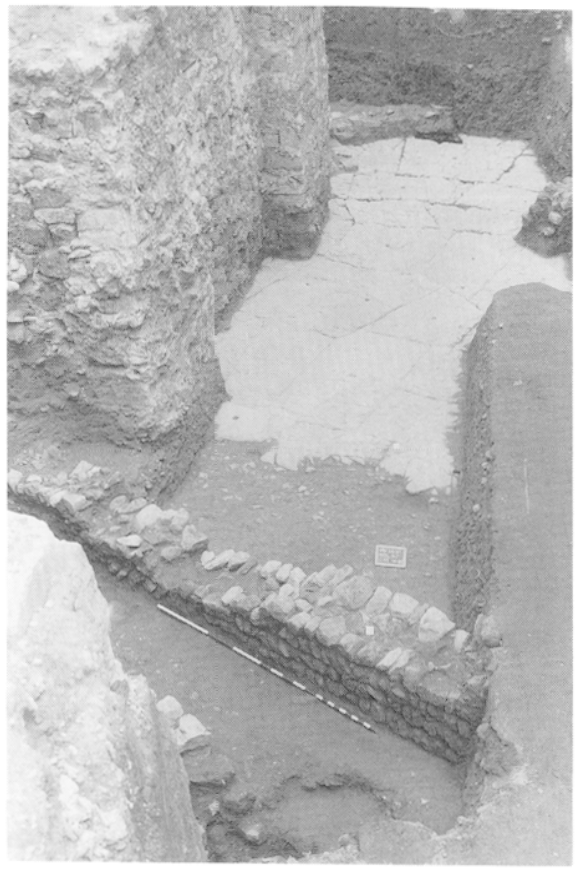

Fig. 22 - Arles aux Ve-VIe s (cf. fig. 19. 19).

Voic et habitats tardifs sur le dallage de l'hôpital Van-Gogh.

- Habitations venant s'installer sur le dallage découvert dans l'hôpital Van-Gogh (19) (fig. 22). L'habitat apparait dès la fin du IVe s. et perdure jusque vers le milieu du VIe s.

Gallia Informations, 1987-1988. 2. p. 233: Sintès. 1987b. p. 44-45: 1994. 


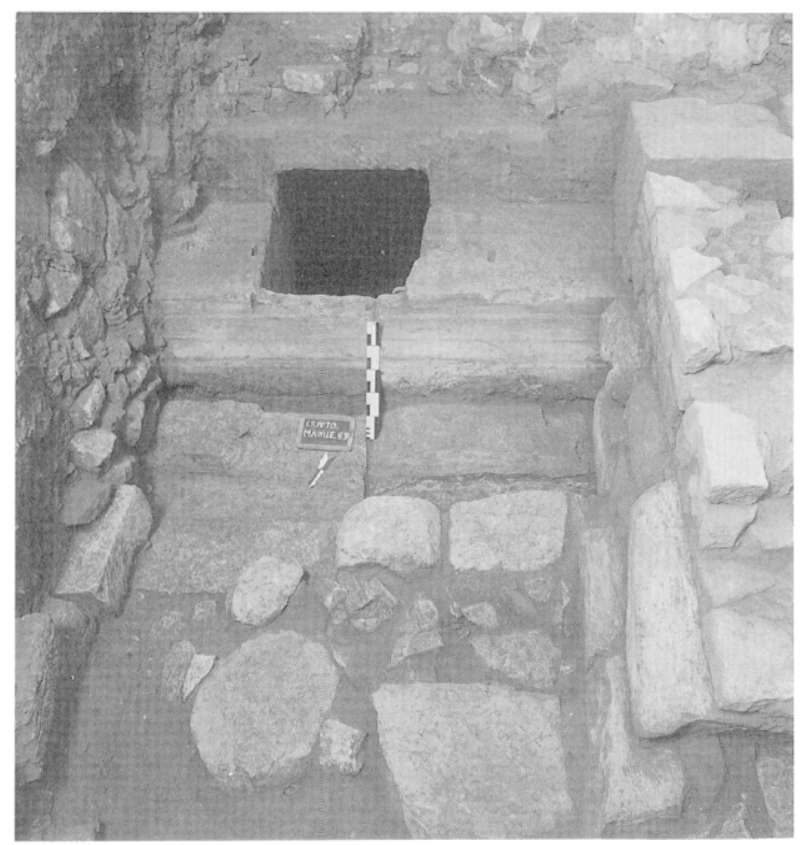

Fig. 23 - Arles aux Ve-VIe s (cf. fig. 19. 20).

Habitat sur le dallage du forum.

- Habitat (20) construit sur le dallage du forum augustéen vers le début du Ve s. (fig. 23). Les galeries souterraines sont également occupées pendant cette période.

Gallia Informations, 1987-1988, 2, p. 233-234:

Heijmans, 1991, p. 175-177: 196 : Sintès, 1994.

- Habitations (?) dans les arènes (21). Si l'on suit G.

Depeyrot, un habitat aurait été installé dans les arènes dès le début du Ves.

Depeyrot, 1983, p. 249.

- Niveaux d'occupation (22), datables du Ve s.. sur le dallage du monument à piédestaux (fig. 6,48 ).

Heijmans. Brémond, 1994 : étude en cours.

- Mur et foyer (23), datables des IVe -Ve s., dans l'église des Frères Prêcheurs.

Etude en cours.

- Niveau du Ve s., au cimetière de Trinquetaille (24). Etude en cours.

- Occupation sporadique de quelques pièces de la villa de la Verrerie (fin IVe début VI' s.) (25).

Gallia, 44, 1986, p. 399: Sintès, 1987f. p. 84 : étude en cours.

- Aménagements de quelques pièces de la villa sur le site de Brossolette, peut-être jusqu'au VIes. (26) (fig. 24).

Gallia Informations. 1987-1988, 2, p. 2.37: étude en cours.

\section{Edifices religieux et funéraires}

- Monastère de femmes fondé par Césaire avec une basilique dédiée à sainte Marie (27). Dans l'enclos se trouvaient d'autres églises dont on a peut-être mis au

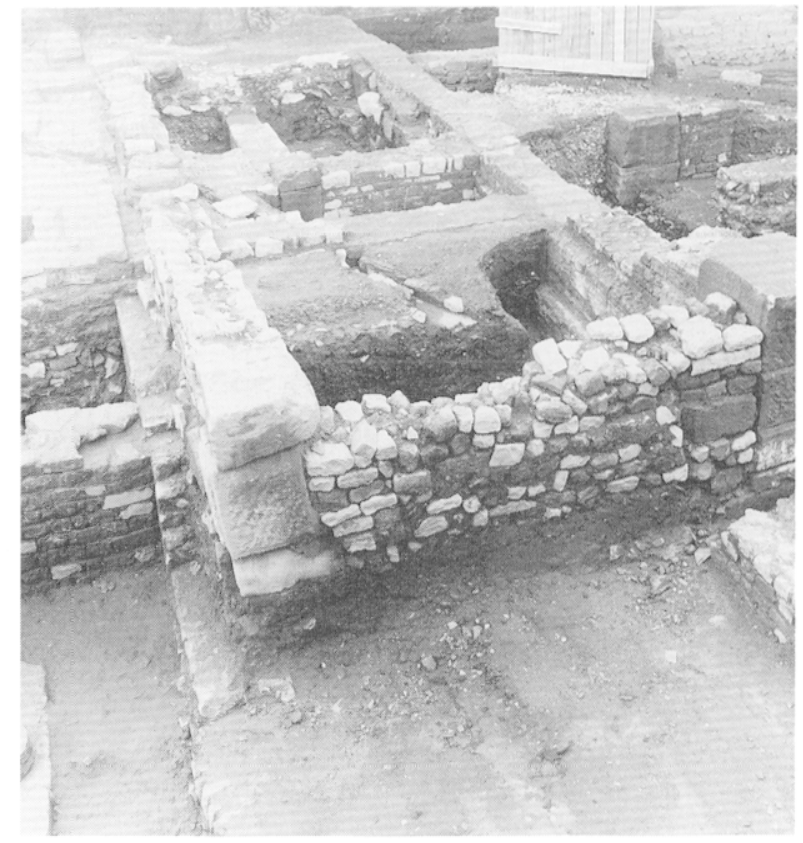

Fig. 24 - Arles aux Ve-VI' s. (cf. fig. 19, 26).

Aménagements tardifs sur la villa de la rue Brossolette.

jour une abside près du rempart. Les sơurs du couvent étaient enterrées dans l'enclos comme Césaire luimême : la découverte de sarcophages et tombes du BasEmpire confirme cet usage. F. Benoit a peut-être découvert les vestiges des citernes dont parle la Vic de saint Césaire à l'occasion d'un incendie.

F.O.R., 51. p. 143; F.O.R. 53. p. 144. 148 : Benoit, 1951b, p. 33-53 : Février, 1986, p. $81, n^{\circ} 6$.

- Basilica sancti Stephani (28). Cathédrale à partir du milieu du Ve s. avec cella des clercs. Il ne reste aucune trace des bâtiments d'origine, sauf peut-être un fragment du dallage (douteux) sous Saint-Trophime.

F.O.R. 104, p. 140. 142 : Benoit. 1951b. p. 53-57: Février, 1986, p. 81, n² 2 .

- Notre-Dame-de-la-Major (29). D'origine incertaine, il s'agit peut-être de la basilica sanctac Mariae dédiée en 524.

Benoit, 1951b, p. 38, 40-41: Février. 1986, p. 81. $\mathrm{n}^{\circ} \mathrm{I}(\mathrm{l}$.

- Monastère d'hommes et basilique in honore sanctorum Apostolorum - actuellement église SainteCroix - (30). Le monastère et la basilique, fondés probablement en 547 par l'évêque Aurélien, sont signalés comme étant intra-muros dans les textes. Le monastère a aussi été utilisé pour l'inhumation des moines.

Février. 1986. p. 82-83, n 11.

- Basilica sancti Genesii - Saint-Honorat-desAlyscamps (31). Des évêques y sont enterrés dès la fin du IVes. Au Ve s., la nécropole continue à fonctionner, mais la série de sarcophages en marbre s'arrête au début du siècle.

Février, 1986, p. 81. n 13. 


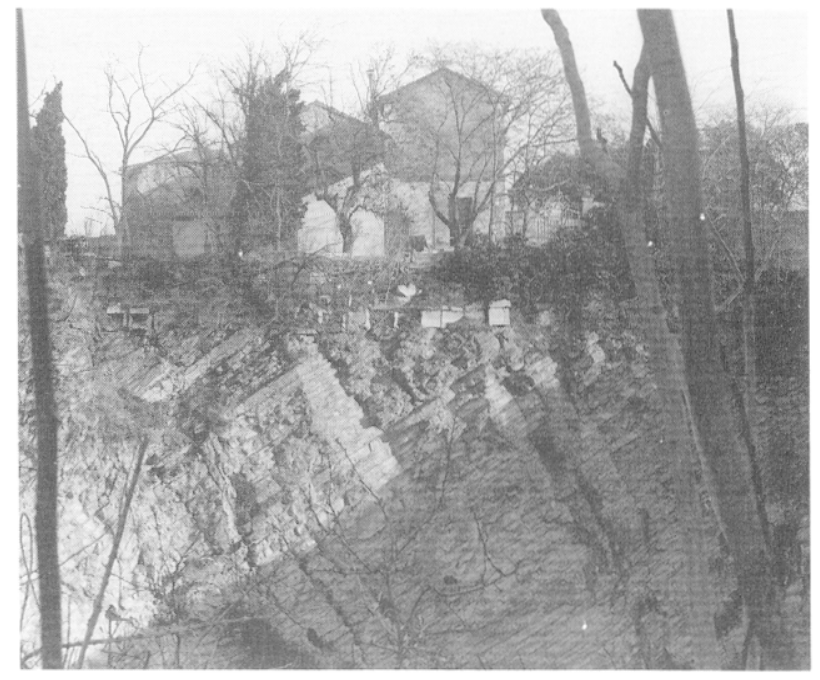

Fig. 25 - Arles aux V'-VIc s. (cf. fig. 19. 32). Sarcophages en place. autour de la chapelle de Saint-Pierre-de-Mouleyrès.

- Basilica sancti Petri et Pauli - Saint-Pierre-deMouleyrès (32) (fig. 25). Fondée avant 530): de très nombreux sarcophages ont été découverts autour de l'édifice lors de la construction des ateliers du P.L.M. au XIXes.

F.O.R., 21, p. 168-169: Février. 1986, p. 84, no 16.

- Saint-Genest-de-Trinquetaille (33). L'existence d'une église à cette époque n'est pas attestée archéologiquement. On a en revanche de nombreux textes littéraires, comme d'ailleurs une grande quantité de sarcophages qui témoignent de la dévotion pour le lieu de culte au Ve et Vİ s.

Février. 1986, p. 84, n¹4.

\section{ARLES DU VIIe AU IXe $S$.}

\section{ÉVOLUTION TOPOGRAPHIgUE (fig. 26)}

A la fin du VÍ s.. Arles entre comme toute la Provence dans une période de difficultés grandissantes et d'obscurité. La documentation, lacunaire jusque-là. manque presque totalement pour ce pan de l'histoire arlésienne. Il est symptomatique que les listes épiscopales soient interrompues et que les textes ne nous éclairent un peu qu'à la fin du IX' ${ }^{\circ}$. seulement. Les données archéologiques manquent elles aussi et notre méconnaissance actuelle du mobilier céramique fait que l'on ne peut dater précisément des couches ou des structures de cette période ${ }^{51}$.

Quelques indications, quelques rares textes permettent à peine d’imaginer la ville durant cette

51 Voir pourtant CATHMA. Céramiques glaçurées de l'Antiquité tardive et du haut Moyen Age en France méridionale, in : L. PAROl.I (ed.). La ceramica invetriata tardoantica e altomediecaie in Italia. Florence, 1992, p. 65-74. période. Dans l'enclos du monastère de femmes, fondé par saint Césaire, l'abbesse Rusticule qui vivait au début du VIIE s. a fait construire une église in honore sanctue Crucis avec sept autels et une chapelle SaintMichel. A cette époque y est située aussi une basilique Saint-Pierre sans que l'on puisse dire à quel moment elle fut fondée. A la fin du IX $\mathrm{X}^{\mathrm{c}} \mathrm{s}$., le monastère est reconstruit après une destruction causée par les invasions normandes et sarrasines. La tombe de saint Césaire est restaurée et un fragment de la nouvelle épitaphe nous est parvenu ${ }^{52}$.

Aux Alyscamps, des sarcophages à cuves renversés, conservées actuellement dans la chapelle Saint-Honorat, montrent l'utilisation de la nécropole à l'époque carolingienne. La partie ouest de la nef de l'église, datée par F. Benoit de l'époque carolingienne, semble être plus tardive si on la compare avec les parties basses de Saint-Trophime.

Il est difficile, cependant, de faire remonter la datation des chapelles (dont on peut constater la présence au Moyen Age) au-delà du Xe s. On connaît quand même une chapelle Sainte-Eulalie à l'ouest de la nécropole qui appartenait à l'abbaye de Saint-Césaire, comme l'indique un texte du IXes. On peut supposer aussi à l'ouest de la chapelle Saint-Césaire-le-Vieux, datée du IXe s., une chapelle plus ancienne.

Un texte du IXes. mentionne aussi une église Saint-Martin qui appartient au monastère de SaintCésaire. S'agit-il de l'église Saint-Martin près du Rhône ou d'une autre église dans, la partie orientale de la nécropole des Alyscamps ${ }^{53}$ ?

A Trinquetaille, la nécropole tardive à l'ouest du quartier est peut-être à rattacher à cette période.

On connaît, d'autre part, deux églises du IXe s.. Saint-André et Saint-Vincent, in insula suburbana sur l'îlot de Cappe en Camargue.

La documentation archéologique est. elle aussi, bien pauvre et seuls deux sites (Van-Gogh et la Major) permettent jusqu'à ce jour de voir une occupation pour les VII - IX' s., grâce au mobilier récolté.

Le dossier pour la période du VIIe au IXe s. est dono bien limité : il est difficile de se forger une idée du mode de vie à cette époque et de la réalité topographique. Il faut quand même noter que lorsque les textes réapparaissent à la fin du IXe s., on découvre une ville dont la «reprise» est déjà sensible.

\section{REPÈRES TOPOGRAPHIGUES}

\section{Enceinte}

- Tour dite «de Roland» (1). Aménagement défensif d'une iravée méridionale du théâtre antique qui paraît devoir être daté de l'épiscopat de l'évêque Roland (IXes.)

52 Benoit, 1935b.

53 Benoit, 1935a, p. 53 : - Février, 1986. p. 84. $n^{\circ}$ a. 


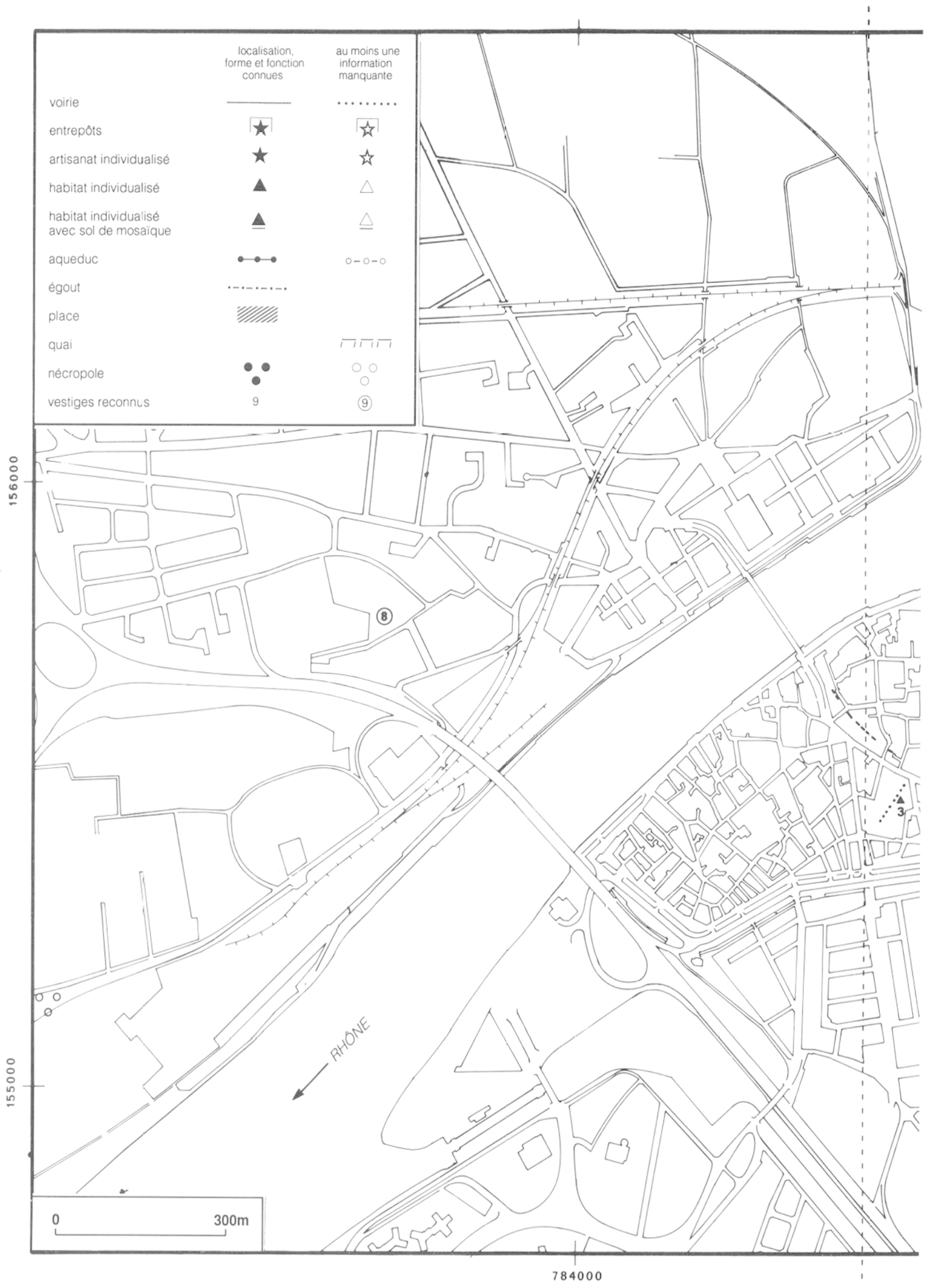




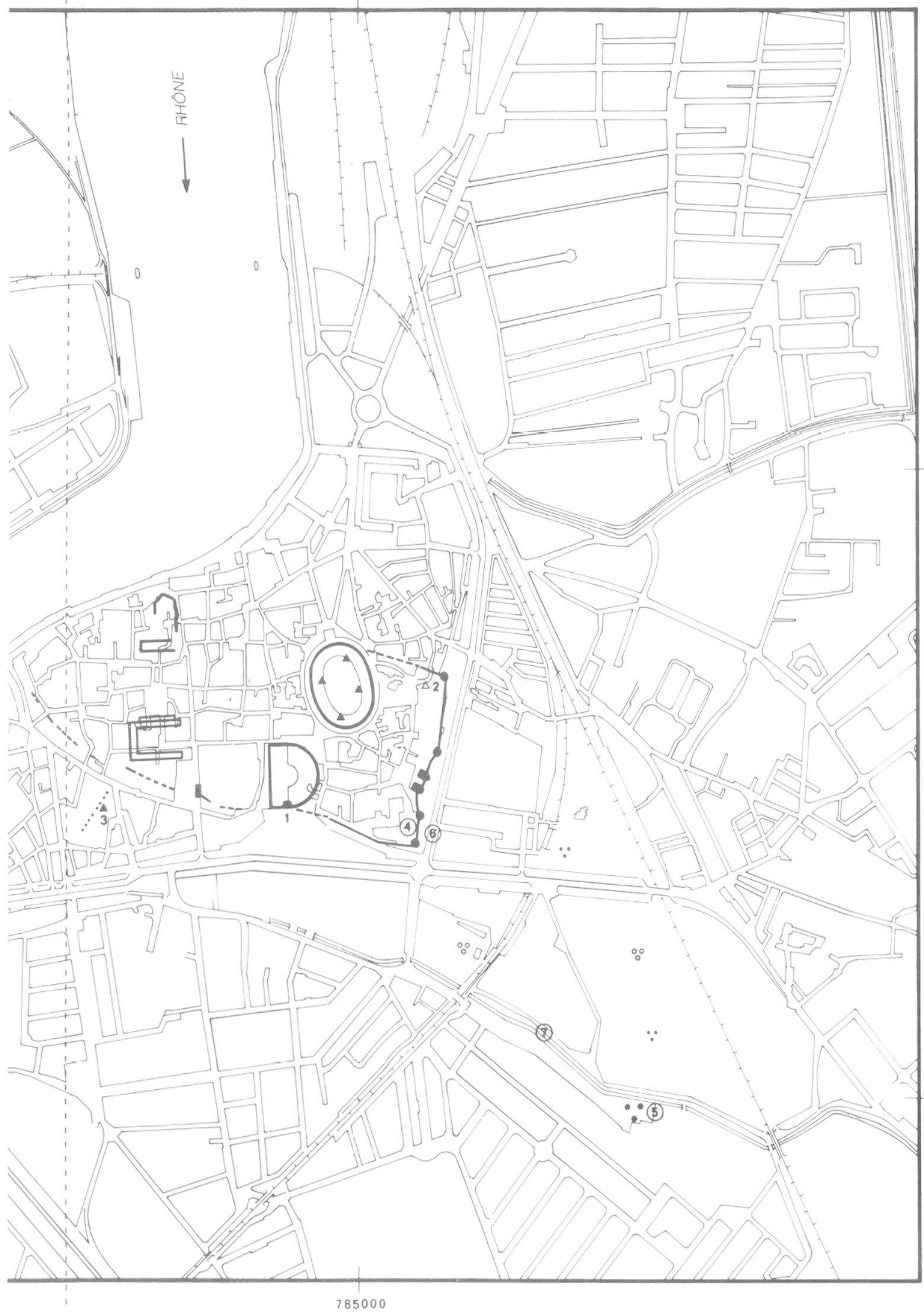

Fig. 26-Plan 5 : Arles aux VII'-IX's. 


\section{Habitat}

- Habitations (2) sur la place de la Major. L'étude du matériel des anciennes fouilles à cet endroit semble montrer l'existence de niveaux homogènes du VIIes.

Etude en cours.

- Site de l'hôpital Van-Gogh (3). Voie datable des VIIeVIIIle s. et fosse à dépotoir (?).

Sintès, 1987b, p. 45.

\section{Edifices religieux}

- Enclos Saint-Césaire (4). Fondation d'une église Sainte-Croix par l'abbesse Rusticule au début du VIIe s. On trouve aussi dans l'enclos une chapelle Saint-Michel et une église Saint-Pierre.

Benoil, 1935b ; 1951b, p. 34-36, 39-53 ; Février, 1986. p. $82, \mathrm{n}^{\mathrm{os}} 7,8$.

- Nef de Saint-Honorat (5); état carolingien?

Sarcophages carolingiens.

Benoit, 1938a, p. 363-365; Rouquette, 1974 a, p. 347.

- Chapelle Sainte-Eulalie (6). Mentionnée dans un texte du IXes.

Benoit, 1935a, p. 57.
- Saint-Césaire-le-Vieux (7) dont la date peut être remontée à une haute époque.

Benoit, 1935a. p. 53.

- Saint-Genest-de-Trinquetaille? (8). Cette église est mentionnée de nouveau à la fin du IX $\mathrm{X}^{\mathrm{c}} \mathrm{s}$. Peut-on dire pour cela qu'elle existe entre le VIe et le IXe s. ou qu'il s'agit d'un édifice complètement neuf qui apparaît à la fin du IXe s. ?

Rouquette, 1974a, p. 358.

Marc HEIJMANS et Claude SINTÈS

Origine des documents -

P. Arcelin (fig. 3, 4); J. Brémond (fig. 1, 5, 6, 7. 11, 14, 19. 26) : M. Heijmans (fig. 2, 8, 10, 11 16, 17, 20, 25): M. Lacanaud (fig. 9, 12, 15, 21 à 24): M. Vecchione (fig. 13, 18).

\section{BIBLIOGRAPHIE}

Abréviations utilisées -

B.A.P. : Bulletin Archéologique de Provence.

B.S.A.V.A. : Bulletin de la Société des Amis du Vieil Arles.

B.A.V.A. : Bulletin des Amis du Vieil Arles.

B.S.N.A.F. : Bulletin de la Société Nationale des Antiquaires de France.

Bull. Arch. : Bulletin Archéologique du Comité.

Bull. Mon. : Bulletin Monume'ntal.

C.A.F. : Congrès Archéologique de France.

C.R.A.I. : Comptes Rendus de l'Académie des Inscriptions.

Doss. Hist. et Arch. : Dossiers Histoire et Archéologie.

Jb.D.A.I. : Jahrbuch des Deutschen Archäologischen

Instituts.

J.R.A. : Journal of Roman Archaeology.

J.R.S. : Journal of Roman Studies.

M.I.H.P. : Mémoires de l'Institut Historique de Provence.

M.S.N.A.F. : Mémoires de la Société Nationale des

Antiquaires de France.

Prov. Hist. : Provence Historique.

R.A. : Revue archéologique.

R.A.N. : Revue Archéologique de Narbonnaise.

R.E.A. : Revue des Études Anciennes.

R.E.Lig. (R.S.Lig.): Rerue des Études Ligures (Rivista di Studi Liguri ).

Rev. Hist. : Revue Historique.

R.M. : Mitteilungen des Deutschen Archäologischen Instituts, Römische Abteilung.

\section{Amy R.}

1973 : Les cryptoportiques d'Arles, in : Les cryptoportiques dans l'architecture romaine (Ecole Frangaise de Rome, 19. 23 aril 1972), Rome, p. 275-291.

Arcelin P.

1987a : Les problèmes urbains: Arles protohistorique, in : Cl. Sintès (ed.) 1987, p. 16-23.

1987b : Les fouilles du Jardin d'Hiver, in : Cl. Sintès (ed.) 1987. p. 24-30.

1990: Arles, in : Vovage en Massalie, Marseille, p. 194-198.

Benoit F.

1929 : L'are de triomphe du Rhône, M.I.H.P.. VI, p. 1.39-154.

1933 : Compte rendu des recherches faites à Trinquetaille en 1933. C.R.A.I. p. 415-419.

1934a : La Tour des Mourgues. Note sur l'enceinte romaine d'Arles, R.E.A., XXXVI, p. 206-212.

19.34b : Les fouilles et la topographic antique de Trinquetaille, M.I.H.P., 11, p. 203-226.

1934c : Compte rendu des recherches faites à Trinquetaille en 1934. C.R.A.I.. p. 343-351.

1935a: Les cimetières suburbains d'Arles dans l'Antiquité chrétienne et au Moyen Age. Studi di Antichità Cristiana. XI, Rome-Paris.

1935b : La tombe de saint Césaire d'Arles et sa restauration en 883, Bull. Mon., 94, p. 137-143. 
1936: Forma Orbis Romani. Carte archeologique de la Gaule romaine, V. Département des Bouches-du-Rhône. Paris.

1938a : L'église Saint-Honorat des Alyscamps à Arles. Etude historique et archéologique, Bull.Mon., p. 353-396.

1938b: Compte rendu des recherches faites à Trinquetalle en 1938, C.R.A.I., p. 541-548.

1938c : La basilique d'Arles, R.A., p. 212-232.

1941 : Essai de quadrilage d'un plan d'Arles, C.R.A.I., p. 92 100.

1943 : Recherches archéologiques en Provence: La tour galloromaine de l'enceinte d'Arles et l'abbaye de Saint-Césaire, Gallia, I, p. 279-285.

1944a: Recherches nouvelles à Trinquetaille (Arles) en 1941 1942, Gallia, II, p. 251-257.

1944b : Le cimetière des Aliscamps, Gallia. II, p. 257-260.

1947 : Cimetières paléochrétiens de Provence. Cahiers Archéologiques, II, p. 7-15.

1951a: Le temple d'Auguste et les cryptoportiques d'Arles. B.S.N.A.F., p. 160-162.

195lb: Le premier baptistère d'Arles et l'abbaye SaintCésaire. Nouvelles recherches sur la topographie paléochrétienne d'Arles du IVe au VIe siècles, Cahiers Archéologiques, V. p. 31-59.

1951c: L'inscription de la place du Forum à Arles, M.S.N.A.F., p. 227-250.

1952 : Le sanctuaire d'Auguste et les cryptoportiques d'Arles, R.A., XXXIX, p. 31-67.

1954 : Sarcophages paléochrétiens d'Arles et de Marseille. ve suppl. à Gallia, Paris.

1957 : Observations sur les cryptoportiques d'Arles, R.E.Lig.. XXIII, p. 107-112.

1963: Les cryptoportiques de la Narbonnaise, Atti del le Congresso Intern. di Arch. dell'Italia Settentrionale. Turin. p. 145-164.

1964: Le développement de la colonie d'Arles et la centuriation de la Crau, C.R.A.I., p. 156-169.

Böhm A.

1992: Die römischen Bogenmonumente der Gallia Narbonensis in ihrem urbanen Kontext. Thèse dactyl., Univ. de Cologne.

\section{Brémond J., Heijmans M.}

1993 : Histoire d'une découverte annoncéc. La Résidence Les Dominicains, B.A.V.A., 82, p. 3-7.

\section{Congès G.}

1980 : Arles: découvertes d'importants vestiges romains, Archéologia, 142, p. 9-23.

1987 : L'Esplanade, in : Sintès Cl., (cd.) 1987, p. 33-37.

Congès A. et Congès $(\mathbf{G}$.

1982 : Arles, in : Archéologie urbaine, Paris, p. 311-318.

Congès G. et alii

1992: L'évolution d'un quartier suburbain d'Arles. L'Esplanade, Prov' Hist., 167-168, p. 120-133.

Congès G., Leguilloux $M$.

1991: Un dépotoir de l'antiquité tardive dans le quartier de l'Esplanade à Arles, R.A.N.. 24, p. 20)-234.

Constans L.A.

1921 : Arles antique, Paris.

\section{Dampeine $\mathbf{M}$.}

1980: Recueil des mosä̈ues des Bouches-du-Rhône et du Var, Thèse de 3e cycle, Univ. d'Aix-en-Provence.
Daniel Ph., Heijmans M.

1992 : Le pont romain d'Arles, B.A.P.. 21. p. 97-106.

Demougeot $\mathbf{E}$.

1974 : Constantin III, l'empereur d'Arles, in : Hommage à André Dupont. Etudes médiévales languedociennes, Montpellier, p. 83-125.

Depeyrot (G.

1983 : Les trouvailles monétaires d'Arles (1976-1980). R.A.N, XVI, p. 247-284.

Euzennat M.

1972: Le monument à rotonde de la nécropole du cirque à Arles, C.R.A.I., p. 404-423.

\section{Euzennat M., Hallier (G.}

1987: La nécropole du cirque, in : Sintès Cl., (ed.) 1987. p. 114-117.

Février P.-A.

1964: Le développement urbain en Provence de l'époque' romaine à la fin du XNV sièrle. Archéologie et histoire urhaine. Paris.

1978: Arles aux IVe el Ve s.. ville impériale el capitale régionale, in : XXV corso di cultura sull'arte ravennate et bizantina, Ravenna 5-15 marzo 1978. Ravenna, p. 127-158.

1983: Aux origines de quelques villes médiévales du Midi de la Gaule, R.S.Lig., XLIX. p. 316-335.

1986: Arles, in: N. Gauthier, J.-Ch. Picard (ed.), Topographie chrétienne des cités de la Ganle. III. Paris. p. 73-84.

\section{Fincker $M$.}

1987 : Arles et Nimes, deux amphithéâtres semblables. Doss Hist. et Arch., 116 p. 40-45.

1990: Du Coliséc à l'amphithéâtre d'Arles: projets et filiations. Recherches pré-liminaires, in: Spectacula $I$. Gladiateurs et amphithéâtres, Lattes, p. 29-37.

\section{Formigé J.}

1912 : La basilique d'Arles, B.S.N.A.F., 419-423.

1948: La date de la construction du théâtre d'Arles, R.A., p. $382-399$.

1951 : Les fouilles d'Arles, B.S.N.A.F., p. 156-158.

1964/1965: L'amphithéâtre d'Arles : histoire ct date de la construction, R.A., 1964/2, p. 21-41, 113-163;1965/1 1-46.

Gladiss A. von

1972 : Der «Arc du Rhône» von Arles, RM. 79, p. 17-87.

Grenier A.

1960: Manuel d'Archéologie gallo-romaine. IV. Les momuments des eaux, Paris.

\section{Gros P.}

1987 : Un programme augustéen: le centre monumental de la colonie d'Arles, JhDAl, 102, p. 339-363.

1991: Nouveau paysage urbain et cultes dynastiques: remarques sur l'idéologie de la ville augustéenne à partir des centres monumentaux d'Athènes, Thasos, Arles et Nimes, in: Les villes augustéennes de Gaule. Autun 1991. p. 127-140.

Guyon J.

1982 : L'évolution des sites urbains en Provence (Antiquité et Haut Moyen Age). L'exemple de Marseille, Aix. Arles et Rie\% à la lumière des recherches et fouilles récentes, Ktima. 7.p. 129-140.

Hallier (s.

1987 : Le cirque romain. in : Cl. Sintès (ed.) 1987, p. 56-62.

Heijmans $M$.

1988: Intra Muros. De laat-antieke stadsmuren in Gallia 
Narbonensis; een probieem ran historische topografie, Mémoire de doctorat, dactyl., Univ. de Leyde.

1991: Nouvelles recherches sur les cryptoportiques d'Arles et la topographie du centre de la colonie, R.A.N., 24, p. 161-199. Thèse en cours : Duplex Arelas. Topographie historique de la ville d'Arles dans l'antiquité tardive.

Heijmans M., Brémond J.

1994 : Trois ans de prospection arlésienne, de la cave jusqu'au grenicr, B.A.P., 24.

Hubert J.

1947 : Recherches sur la topographic religicuse d'Arles au Ve s., Cahiers Archéologiques, 2, p. 17-27.

Humphrey J.

1986 : Roman Circuses. Arena for Chariot Racing, Londres, p. $390-398$.

Latour J.

1953 : Le sanctuaire d'Auguste et les cryptoportiques d'Arles, R.A., XLII, p. 42-51.

Piton J.

1988 : Elude comparative entre les importations Africaines et les productions de la vallée du Rhône. Fin IIJe-début IVe $s$., S.F.E.C.A.G., Actes d'Orange 12 - 15 mai 1988, Marseille, p. $81-90$.

Rouquette J.-M.

1974a: Provence romane, la Prolence rhodanienne, LaPierre-qui-Vire.

1974b: Trois nouveaux sarcophages chrétiens de Trinquetaille (Arles), C.R.A.I.. p. 254-277.

1976: Arles, Livret-guide de l'excursion C3 du IXe Congrès de l'Union Internationale des Sciences Préhistoriques et Protohistoriques, Nice 1976. p. 101-121.

1980 : La villa romaine dis Crédit Agricole. Arles.

1987a : Les découvertes du Crédit Agricole, in : Sintès Cl. (ed.) 1987, p. 71-77.

1987b : L'enceinte primitive de la colonic romaine d'Arles, in : Colin, M.-G. (ed.), Les enceintes augustéennes dans l'occident romain. Nimes, p. 97-102.

1989 : Trinquetaille, les fouilles anciennes, B.A.V.A., 68 , p. 11-17.

Rouquette J.-M., Sintès Cl.

1989: Arles antique. Monuments et sites, Guides archéologiques de la France, 17, Paris.

Sintès Cl.

1987a : L'habitat du haut-empire au Jardin d'Hiver, in : Sintès Cl., (ed.) 1987, p. 41.

1987b : Les fouilles de l'hôpital Van-Gogh, in : Sintès Cl., (ed.) 1987. p. 44-48.

1987c : La rue Dicudonné. in : Cl. Sintès (ed.) 1987, p. 51.

1987d : Les zones suburbaines, in : Cl. Sintès (ed.) 1987. p. $53-5.5$.

1987e : Le Cirque romain. Les fouilles récentes, in : Cl. Sintès (ed.) 1987, p. 6.3-65.

1987f : Les fouilles de la Verrerie de Trinquetaille, in : Cl. Sintès (ed.), 1987, p. 81-84.

1987g : Les nécropoles, in : Cl. Sintès (ed.) 1987, p. 95-99.

1987h : La nécropole protohistorique de l'hôpital Van-Gogh, in : Cl. Sintès (ed.) 1987. p. 100-103. 1987i : Rochefleur, in : Cl. Sintès (ed.) 1987, p. 105-106. $1987 \mathrm{j}$ : La nécropole du Jardin d'Hiver, in : Cl. Sintès (ed.) 1987, p. 121.

1987k : Les sarcophages de Trinquetaille, in : Cl. Sintès (ed.) 1987, p. 124.

1989 a : Fouilles récentes à Arles. Un état de la question, R.A., p. 203-210.

1989b: Vicissitudes d'un théâtre antique, Doss.Hist.Arch., 134, p. 26-29.

1989c: Trinquetaille, les fouilles récentes, B.A.V.A., 68, p. 18-23.

1990a : Le résultat des fouilles, in : Cl. Sintès (ed.) 1990. p. 11-16.

1990b: Quelques remarques sur la spina du cirque d'Arles, in : Ch. Landes (ed.), Cirques et courses de chars. Rome Byzance, Lattes, p. 55-63.

1992 : L'évolution topographique de l'Arles du haut-empire à la lumière des fouilles récentes, $J . R . A . .5, \mathrm{p} .130-147$.

1994: La réutilisation des espaces publics à Arles, un témoignage de la fin de l'antiquité, Antiquité lardiv'e, 2.

Sintès Cl. (ed.)

1987: Du nowreau sur l'Arles antique (= Revue d'Arles 1), Arles.

1990 : Carnets de fouilles d'une presquîle (= Rev'ue d'Arles 2), Arles.

Sintès Cl. et alii

1990): Documents d'Éraluation du Patrimoine Archéologique Urbain-Arles. Paris.

Véran A.

1903 : Rapport sur les fouilles du rempart d'Arles en 1902, Bull. Arch., p. 216-222.

1904 : Le Palais de Constantin, dit Palais de la Trouille à Arles, B.S.A.V.A., 1, p. 97-107.

1908 : Arles souterraine. le forum et la basilique, B.S.A.V.A. V.p. 285-314.

1910 : La basilique d'Arles, C.A.F., LXXVIe session, Avignon 1909. Paris-Caen, p. 185-190.

Wheeler R.E.M.,

1926: The Roman town-walls of Arles, J.R.S., 16, p. 174 194.

N.B.- De nombreuses informations sont issues des Bilans scientifiques et des Notes d'informations et de liaisons du Service régional de l'Archéologic de Provence-Alpes-Côte d'Azur. Celles-ci n'étant pas à proprement parler des publications nous ne faisons ici qu une mention générale : - N.I.L.P.A.C.A.. 3, 1986, p. 66-67 : 4, 1987, p. 74, 77-78: 5, 1988 , p. 64-65, 68-76:6, 1989, p. 88-90) 7, 1990, p. 75-78: - Bilans scientifiques, 1991, p. 85-87: 1992, p. 116-117. 